\title{
REINTEGRACIÓN DE UN TERRITORIO ENTRE FRONTERAS: EL ALTO SEGRE, PIRINEOS
}

\author{
M. Pallarès-Blanch ${ }^{1}$ \\ Fundación Centre de Desenvolupament Rural Integrat de Catalunya, \\ programa Talent-Empresa. C/ Coll de Jou 25280 Solsona, Lleida, España \\ marta.pallares@gmail.com
}

\begin{abstract}
A.F. Tulla Pujol y A. Vera Martín
Departament de Geografia, Universitat Autònoma de Barcelona (UAB) Edificio B, Facultat de Filosofia i Lletres, Campus de Bellaterra 08193, Barcelona, España antoni.tulla@uab.cat - ana.vera@uab.cat
\end{abstract}

Resumen: Los valles de la cuenca alta del río Segre tienen elementos de identidad comunes. Entre los siglos XIII y XVII se produce la división político-administrativa de este territorio, repartido actualmente en tres estados diferentes (España, Francia y Andorra). La región comprende cuatro áreas diferenciadas; Alt Urgell y Baixa Cerdanya (comarcas catalanas en España), Alta Cerdanya (comarca natural en Francia) y el Principado de Andorra. Las cuatro áreas han desarrollado distintas especializaciones económicas, afectadas por la actual crisis de la burbuja inmobiliaria. La cooperación entre estos territorios se refleja principalmente en los flujos transfronterizos por razones de trabajo, de compras y acceso a los servicios, adquisición de viviendas permanentes y estacionales y en actividades culturales. Ante el nuevo escenario, son deseables modelos de desarrollo sostenibles con servicios público-privados mancomunados que pueden ser recogidos por las políticas de cooperación territorial de la UE en un plan común.

Palabras clave: cooperación transfronteriza, identidades trans-territoriales, Pirineos, desequilibrios territoriales, globalización.

Abstract: The valleys of the upper Segre river basin have common identity elements. Between the XIII y XVII centuries takes place the political-

Recibido: 30-04-13. Aceptado: 5-11-13.

1. Su trabajo de investigación en este artículo está vinculada a su programa de Doctorado de la UAB. 
administrative division of the territory, currently distributed in three different states (Spain, France and Andorra). The region comprises four distinct areas; Alt Urgell and Cerdanya Low (Catalan regions in Spain), Cerdanya High (natural region in France) and the Principality of Andorra. The four areas have developed different economic specializations, affected by the current crisis in the housing bubble. The cooperation between these areas is mainly reflected in cross-border flows for work, shopping and access to services, acquisition of permanent and seasonal housing and cultural activities. In the new scenario, are desirable sustainable development models with joint public-private services that may be collected by the policies of EU territorial cooperation in a common plan.

Key words: cross-border cooperation, trans-territorial identities, Pyrenees, Spatial inequalities, globalization.

\section{Introducción}

El objetivo del artículo es valorar, en el contexto de cooperación transfronteriza abierto por la Unión Europea, la capacidad de reintegración de una región histórica localizada en la Cuenca alta del río Segre en los Pirineos. La región del Alto Segre la forman los territorios de: (1) el Principat d'Andorra (en adelante Andorra), (2) las comarcas catalanas del Alt Urgell -en territorio español- y (3) de la Cerdanya, dividida ésta entre la Baixa Cerdanya, en territorio español y (4) la Alta Cerdanya, en territorio francés. Las cuatro unidades territoriales conservan elementos de identidad común tan relevantes como la lengua vernácula, el catalán, aspectos de la cultura popular y lazos familiares de primer, segundo y tercer grado. Las cuatro áreas tuvieron una organización política común desde el siglo VIII como condados del Imperio Carolingio en la Marca Hispánica. El proceso de separación se produjo entre los siglos XIII y XIX: el Principado de Andorra se independiza en el XIII del actual Alt Urgell ${ }^{2}$, Alta Cerdanya ${ }^{3}$ se incluye en territorio francés en el XVII y Baixa Cerdanya se divide entre la provincia de Lleida y la de Girona a raíz de la división territorial española de 1833.

2. La comarca del Alt Urgell (división territorial de Catalunya de 1933) ocupa el sector norte de lo que fue el Condado de Urgell. Comprendía los territorios que actualmente corresponden a la propia comarca, junto con Andorra y partes de las comarcas del Solsonès, la Segarra y la Noguera. El Condado de Urgell se creó en el año 785 y se mantuvo hasta 1413, cuando se integró a la Corona de Aragón.

3. La Alta Cerdanya, junto con las comarcas; el Capcir, el Conflent, el Rosselló y el Vallespir forman la Catalunya Nord. Representan la casi totalidad del Departamento de los Pyrénées-Orientales, que se reparte en 3 arrondissements; Perpignan, Céret y Prades. Prades se divide en seis cantones; Mont-Louis, Olette, Prades, Saillagouse, Sournia y Vinça. Mont-Louis y Saillagouse son los cantones que conforman la parte francesa de la Cerdanya. 
A pesar de estas divisiones territoriales las cuatro áreas, de características geográficas semejantes, han conservado vínculos sociales, culturales y económicos. Sin embargo, las condiciones político-administrativas han dado lugar a especializaciones económicas diferentes. Tales diferencias, fomentan de una parte la complementariedad entre estos territorios, aunque por otra parte, su situación periférica respecto los centros políticos del Estado francés y el Estado español, y el hecho que Andorra no sea un país comunitario, obstaculizan la cooperación. Tanto el incremento de flujos, como el actual contexto de crisis, son razones que invitan a fomentar medidas para compartir servicios e infraestructuras así como potenciar una agenda política encaminada a un desarrollo local con objetivos comunes. Con la creación de la Unión Europea (UE) se han abierto nuevos escenarios económicos y políticos en los que plantear acciones de cooperación entre territorios. Las políticas de cooperación territorial de la UE ofrecen instrumentos específicos para la cooperación institucional entre territorios transfronterizos que son oportunidades para una nueva gobernanza en determinados ámbitos de los servicios públicos y privados con acciones de gestión mancomunada y de planificación territorial integrada.

El presente artículo consta de siete apartados: (1) Introducción, (2) Metodología y fuentes, (3) Marco teórico, (4) Características geográficas e históricas del área de estudio, (5) Análisis demográfico, espacial y socioeconómico e identificación de los flujos en la Región del Alto Segre, (6) Perspectivas de integración de la Región del Alto Segre y (7) Conclusiones.

\section{Metodología y fuentes}

Este estudio se ha podido realizar mediante la combinación de fuentes de diversas procedencias. Por un lado, disponemos de los estudios regionales sobre la zona, que abrazan un amplio período temporal. En su mayor parte, se trata de documentos centrados en una de las cuatro áreas de estudio o bien sobre la relación entre dos de ellas, generalmente entre Alt Urgell y Andorra, como el de Estel Margarit (2012) o bien entre Alta Cerdanya y Baixa Cerdanya, como es el caso de Pau Vila (1926), el más antiguo. No se han identificado hasta la fecha documentos referidos al conjunto de la región, tal y como es nuestro objetivo con el presente artículo. Por otro lado, y dada la heterogeneidad del tipo de información procedente de las fuentes secundarias, se aplican metodologías cuantitativas como los indicadores de evolución demográfica y de concentración espacial relativa de la población (Smith, 1975) y de especialización económica con el fin de comparar las cuatro áreas. En concreto, se calcula la población relativa y la población ocupada relativa de las cuatro áreas que integran la zona de estudio en seis momentos históricos: 1787, 1857, 1900, 1950, 1975 y 2011. La población es la variable disponible y comparable más representativa de la capacidad económica del territorio estudiado. Por ello se valora la concentración espacial de la población mediante el cálculo del Índice de Gini 
(Smith, 1975) ${ }^{4}$ y se elabora su representación gráfica: la Curva de Lorenz. El diagrama o curva de Lorenz permite analizar la relación entre dos variables, que en este caso son la población y la superficie de las cuatro áreas que integran la zona de estudio en los seis momentos históricos seleccionados. Aplicamos la variante del método que permite comparar distintos años, tomando por referencia para la variable $(y)$ la que presenta un carácter más estable, que en nuestro caso es la superficie (Taylor, 1977) ${ }^{5}$.

Las fuentes estadísticas utilizadas son las bases de datos del Instituto Nacional de Estadística de España (INE); del Instituto de Estadística de Catalunya (IDESCAT), del Departamento de Estadística del Gobierno de Andorra y del Institut National de la Statistique et des Études Économiques (INSEE). La Alta Cerdanya para efectos estadísticos está representada en los cantones de Saillagouse ${ }^{6}$ y el de Mont-Louis ${ }^{7}$ Otra fuente de datos son los documentos oficiales, mayormente jurídicos, generalmente disponibles en la red, facilitándose el enlace en el apartado de Notas, al final del texto.

Finalmente, los resultados del análisis cuantitativo se han contrastado con la información procedente de entrevistas a representantes o miembros de: Ministerio de Asuntos Exteriores del Gobierno de Andorra, Ministerio de Agricultura de Andorra, Dirección del Instituto de Promoción y Desarrollo del Alt Pirineu i Aran (IDAPA), Oficina Comarcal d'Agricultura de l'Alt Urgell, Presidencia del Consell Comarcal de la Cerdanya, Presidencia de la Agrupación Europea de Cooperación Territorial Pirineos-Cerdanya $(\text { AECTPC })^{8}$, Presidencia del Consell Comarcal del Alt Urgell, Alcaldia de Nahuja, Archivo Comarcal del Alt Urgell, Archivo Histórico de la Cerdanya, Institut d'Estudis Andorrans, Institut d'Estudis Ceretans, Institut d'Estudis de l'Alt Urgell, Societat Andorrana de Ciències, Grups de l'Alt Pirineu, Parc Natural del Cadí-Moixeró, Parc Naturel Régional des

4. El Indice de Gini es el valor que se obtiene a partir de relacionar dos variables, la $x$ y la $y$, que en este caso corresponden a la población y la superficie respectivamente: $\mathrm{I}_{\mathrm{d}}=1 / 2 \bullet\left(\mathrm{x}_{\mathrm{i}}-\mathrm{y}_{\mathrm{i}}\right)$; donde: $x_{i}$ es el valor relativo no acumulado de la población, y $y_{i}$ el valor relativo no acumulado de la superficie en cada caso (Smith, 1975).

5. La curva de Lorenz se interpreta observando la distancia creada entre la diagonal del diagrama y cada una de las líneas curvas. La diagonal (Equality) es la línea recta que une el punto de origen $(0,0)$ con el de destino $(100,100)$ e indica una relación de distribución equitativa de la población en el territorio. Las curvas unen los puntos correspondientes a los valores de la población relativa acumulada de las cuatro áreas para cada uno de los seis años seleccionados. Cuanto más alejada esté la curva de la diagonal indica una mayor desproporción entre la población y la superficie. En cambio, cuanto más próxima esté la curva a la diagonal, más equilibrada será la distribución de la población respecto al territorio (Tulla, 1977).

6. El Cantón de Sallagosa incluye las communes (municipios) de: La Tor de Querol, Porta, Porté, Enveig, Ur, Dorres, Angostrina i Vilanova de les Escaldes, Guingueta d’Ix i Càldegues, Naüja, Santa Llocaia, Palau de Cerdanya, Osseja, Vallcebollera, Estavar, Sallagosa i Llo, Er, Eina, Targasona, Èguet, i Font-romeu, todos de la Alta Cerdanya.

7. El Cantón de Montlluís incluye las communes de: Bolquera, la Cabanassa, Montlluís, Sant Pere de Forcats i Planès en Alta Cerdanya, las communes de La Llaguna, els Angles, Matamala, Formiguera, Puigbaladó, Real i Font-rabiosa de la comarca del Capcir y dos communes de la comarca del Conflent: Fontpedrosa i Sautó.

8. Agrupació Europea de Cooperació Territorial Pirineus-Cerdanya; Groupement européen de coopération territoriale Pyrenées-Cerdagne (GECT). 
Pyrénées Catalanes, Editores de la Revista Mirmanda y técnicos de la Cooperativa lechera Cadí (Cadí S.C.C.L.) en la Seu d'Urgell, la Cooperativa Pirenaica de servicios agrarios (Pirenaica S.C.C.L.) en la Seu d'Urgell y la Société Coopérative Agricole Laitière de Cimelait en Err.

\section{Marco teórico}

Una de las corrientes dominantes en los estudios sobre las fronteras es la que encauza sus efectos a través de la óptica de las regiones, entendidas éstas como unidades espaciales que comparten una serie de elementos comunes. Hartshorne (1932) fue uno de los pioneros en el estudio de las regiones transfronterizas diagnosticando que se trata de zonas fuertemente condicionadas por las interacciones y los flujos específicos que se generan, con los consecuentes acuerdos trans-estatales que de ellos se derivan. La intensidad de los flujos y las formas concretas de cooperación pueden variar mucho en función de las peculiaridades de cada región transfronteriza. A pesar de la importancia de los aspectos económicos, las fronteras son tanto producto de la historia política, y el poder, como de las cuestiones sociales y culturales (Paasi, 2003). Así, Houtum (2002) distingue tres grandes enfoques para el estudio de las fronteras, desarrollados prácticamente de forma diacrónica. En primer lugar, destaca el enfoque de flujos de bienes, servicios y personas, que está fuertemente basado en la división internacional del trabajo, las ventajas comparativas, las diferencias de costes, y la intensidad de las interacciones transfronterizas. En segundo lugar, señala el enfoque de la cooperación entre regiones, que tiene una clara orientación institucionalista, dado que es a través de las instituciones que se pueden establecer planes de desarrollo común y llegar a una mayor integración. En tercer lugar, reconoce el enfoque humano, en el que los factores psico-sociales y de conducta son decisivos para comprender las identidades que se producen y reproducen en las regiones transfronterizas.

El acelerado proceso de globalización de las últimas décadas tiene un papel crucial en la regeneración de las fronteras y en la ampliación de sus funciones. La globalización ha activado la transnacionalización superando, en gran medida, las limitaciones que antiguamente constituían las fronteras (Retaillé, 2010; Newman, 2006). Perkmann (2003) pronostica que el proceso de globalización incrementará los vínculos económicos, políticos, culturales e informacionales entre fronteras, beneficiando a su vez, la propagación de la cooperación transfronteriza. Al mismo tiempo, los límites de los estados son aún considerados elementos centrales en la organización de las actividades económicas y en la protección de los intereses económicos (Scott, 2012; Moncusí, 2008). En consecuencia, hay que tener en cuenta la faceta multidimensional de las fronteras y su rol dual. Las fronteras miran tanto hacia dentro como hacia fuera porque unen y dividen, a la vez que incluyen y excluyen. Por lo tanto, las fronteras, producen identidades ambivalentes. En ellas se puede encontrar al mismo tiempo la inseguridad y la seguridad, 
la cooperación y la competencia. Tales dicotomías pueden cambiar a través del tiempo e incluso producirse de forma simultánea, porque las fronteras son periferias de infiltración, transición y separación (Anderson 1999, Kessler, 2007).

El estudio de las regiones transfronterizas ha tomado especial protagonismo a raíz de la creciente cooperación entre determinadas regiones fronterizas. El concepto de cooperación territorial puede entenderse como "la colaboración más o menos institucionalizada que se desarrolla entre autoridades y/o entidades sub-estatales de uno o varios estados, y su máximo exponente es la creación de organismos de cooperación de políticas y acciones coordinadas tanto a nivel vertical como horizontal" (Oliveras et al., 2010 p. 24). Según sean los actores, los tipos de cooperación y también las características del espacio, darán lugar a diversas modalidades de cooperación territorial. Una de ellas es la cooperación transfronteriza, diferenciada de otras formas porque la colaboración se establece entre autoridades pertenecientes a dos o más estados, con contigüidad geográfica y, por tanto, con una frontera interestatal común. La intensificación de la cooperación transfronteriza se ve reflejada en las más de setenta regiones transfronterizas existentes actualmente en Europa, conocidas por Eurorregiones o Comunidades de Trabajo (Perkmann, 2003).

Una clasificación de tipos de cooperación transfronteriza es la que establece cuatro categorías, definidas por el peso de dos variables clave: 1) la intensidad de cooperación (alta o baja), cambiante según el grado de capacidad estratégica de los organismos implicados, así como el nivel de autonomía jurídica y organizativa de éstos, y 2) la escala de la cooperación (micro y macro) y los niveles administrativos predominantes: local y regional (Oliveras et al., 2010). Los tipos de cooperación transfronteriza resultantes, de acuerdo con los anteriores autores son: a) El de micro-cooperación integrada local, con personalidad jurídica (de derecho público o privado), asociado mayormente con la participación de agentes locales (de NUTS 9 3, LAU ${ }^{10} 1$ y LAU 2), b) El tipo de macro-cooperación integrada, definida por la misma intensidad de cooperación, pero con un ámbito territorial de actuación igual al orden regional (NUTS 2 y 1), c) La micro-cooperación emergente, que recoge acuerdos o convenios entre agentes sub-estatales (con o sin estructura formal) sin personalidad jurídica, por lo que el ámbito territorial de actuación es inferior al regional. d) Por último, la macro-cooperación emergente, referida a una baja intensidad de cooperación, si bien con una actuación asociada con el nivel de los agentes regionales.

9. NUTS son las siglas en francés por "Nomenclatura de las Unidades Territoriales Estadísticas", utilizadas por la UE con fines estadísticos. Están jerarquizadas a tres niveles por tramos de tamaño de población. El nivel 1 en España corresponde a los Grupos de Comunidades Autónomas, el nivel 2 a las Comunidades y Ciudades Autónomas y el nivel 3 a las provincias.

10. "Local Administrative Unit" (LAU) son las unidades administrativas de nivel local de la UE. Se reconocen dos niveles: LAU 1 (no aplicado en España) y LAU 2 (en España corresponde a los municipios). 
Otra tipología es la que propone Medeiros (2011), quien recoge cuatro tipos de enfoque. En primer lugar, distingue el modelo de cooperación total, donde prácticamente no existirían barreras, muy infrecuente. En segundo lugar, identifica una cooperación estructural entre regiones, no ya solo por razones históricas y culturales sino por existir acuerdos funcionales y operativos entre las instituciones de la región. En tercer lugar, indica una cooperación incipiente, generalmente, emprendida a raíz de programas europeos, pero que proporciona una mayor integración de la región. En cuarto lugar, incluye una pseudo-cooperación, en la que existen acuerdos de cooperación, pero carentes de contenido (Medeiros, 2011 en Nelles y Walther, 2011).

Sea cual sea el tipo de cooperación transfronteriza, existe consenso en que, en general, aporta claros beneficios, ofreciendo nuevas oportunidades de desarrollo, humano y económico (Isfanescu, 2011). Estos beneficios son más evidentes en el caso de la cooperación transfronteriza entre grandes ciudades o entre estados miembros que ocupan posiciones centrales en la UE. Sin embargo, estos beneficios son mucho más inciertos en el caso de estados o regiones en situación periférica, dentro del marco de la UE (Niebuhr, 2002). Anteriores investigaciones han señalado que la naturaleza y duración de los proyectos de cooperación transfronteriza llevados a cabo hasta el momento, así como la ausencia de modelos precedentes de gobernanza transfronteriza, no permiten construir verdaderos proyectos de territorio integrado (Ensellem, 2010). Este parece que es el caso de la cuenca alta del río Segre, entre Francia y España, según plantean las autoras de un estudio reciente (Maury, 2011). En él se expone que a pesar de las similitudes culturales y las barreras relativamente insignificantes para la comunicación transfronteriza y a pesar de que existen instituciones de cooperación para la gobernabilidad, como el Comité de la Cuenca del río Segre, en gran parte, todavía están por construir acuerdos y acciones concretas. La desconfianza hacia los intereses particulares y hacia las capacidades gubernamentales entre los actores de un lado y otro de la frontera, junto con las discrepancias entre las autoridades españolas y catalanas, hacen difícil identificar qué actores tienen las competencias para hacer frente a los problemas colectivos de la gestión del agua. Según Nelles y Walther (2011), este es un caso de cooperación transfronteriza que se exhibe como poco funcional, aunque muestre correspondencia con el modelo de cooperación estructural señalado por Medeiros.

Existe en todo el contexto europeo, especialmente en los estados miembros del sur de Europa, una creciente demanda por parte de las entidades locales y regionales de una toma de decisiones más participativa y democrática, que cuente con el saber y la complicidad de los actores locales (Romero, 2009). Así, progresivamente, las entidades sub-estatales buscan acceder a la toma de decisiones multilaterales y una de las posibles vías de acceso a ella es participando en redes de cooperación trans-nacional y transestatal (Happaerts et al., 2010; Oliveras et al., 2010). Para Happaerts et al. (2010) las entidades sub-nacionales son importantes por tres razones; dan significación a los ecosistemas y los usos de los recursos, son responsables de la gestión de programas como los Fondos Estructurales, y, siendo más cercanas a los ciudadanos, son instrumentos básicos para mediar la participación de los actores, elemento esencial, a su vez, para 
la eficacia en los procesos de sostenibilidad. Con la creciente complejidad de la gestión pública, junto con el aumento de las necesidades de la población, se ha producido una progresiva descentralización de las competencias del Estado central, que ha sido simultánea al aumento de competencias por parte de las administraciones locales y regionales (Romero, 2009). Sin embargo, las actuales reducciones en inversiones públicas y las dificultades de financiación de los municipios, especialmente en España, amenazan esta tendencia descentralizadora. En este contexto, son interesantes las reflexiones sobre el rol que la sociedad civil ejerce, y el que potencialmente puede ejercer, en las nuevas formas de cooperación política, económica y socio-cultural en la emergente Europa de la vecindad (Scott, 2010).

\section{Características geográficas e históricas del área de estudio}

La zona de estudio, con $3.178,7 \mathrm{~km}^{2}$ comprende cuatro ámbitos territoriales: (1) Andorra, con 468,0 km² (14,7\%) y 78.115 habitantes en 2011, es el único estado soberano dentro la región. Andorra no es miembro de la UE, aunque disponen de acuerdos bilaterales. Al sur de Andorra, (2) la comarca catalana del Alt Urgell con 1.447,7 km² (45,6\%) y 22.008 habitantes en 2011, que pertenece a la provincia de Lleida. Al este de la anterior, (3) la comarca catalana de la Baixa Cerdanya, con $546,5 \mathrm{~km}^{2}$ (17,2\%) y 18.783 habitantes en 2011, que está dividida entre las provincias de Lleida y Girona. Alt Urgell y Baixa Cerdanya, en tanto que comarcas catalanas en territorio español se incorporan a la UE en 1986. Al noreste de la Baixa Cerdanya, se encuentra (4) la Alta Cerdanya y el Capcir, con 716,5 $\mathrm{km}^{2}$ (22,5\%) y 15.487 habitantes en 2011, que pertenecen al Departamento de PyrénéesOrientales del Estado francés, miembro de la CEE desde 1958 (Figura 1).

A nivel geográfico, la región coincide casi en su totalidad con la cuenca alta del río Segre, que nace en Francia, junto a su tributario La Valira, que emerge en Andorra y desemboca en el Segre en la Seu d'Urgell. Por la vertiente este de la cuenca del Segre, en su parte alta, se abren los valles de cabecera de los ríos Aude y Têt, en territorio francés (Figura 2).

La constitución de los condados de la Marca Hispánica por el Imperio Carolingio, en el siglo VIII, define esta zona de montaña bajo la misma jurisdicción política y administrativa (Condado de Urgell y Condado de Cerdanya) (Valls et al., 2002). A partir del siglo XIII la región se reparte en ámbitos político-administrativos diferenciados. La primera división se produce con la creación de Andorra en el año 1278, separándose del Condado de Urgell. Más adelante, el Tratado de los Pirineos, en el año 1659, marcaría los límites desde el valle de Andorra hasta el Mediterráneo ${ }^{11}$, aunque hasta los

11. En 1660, al desarrollarse el artículo 42 del Tratado de los Pirineos, los representantes de Francia y España aceptaron la exclusión de Llívia de la parte francesa por su condición de Villa y no aldea. 


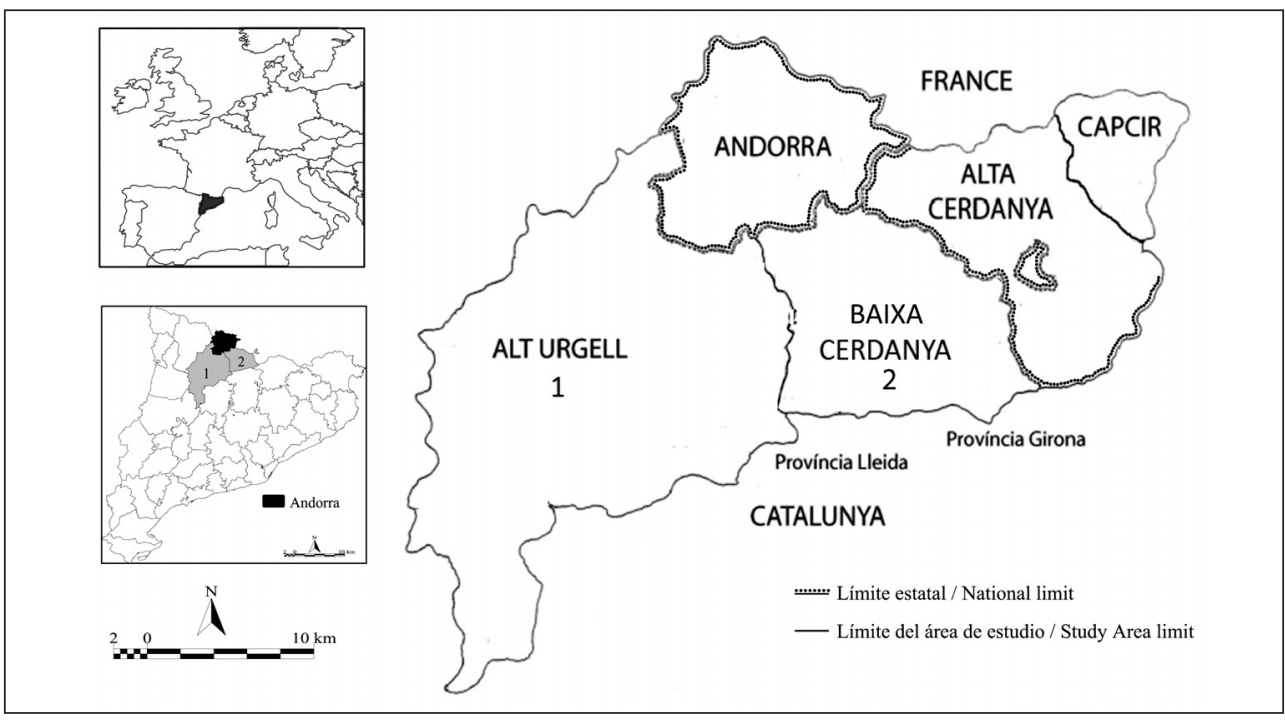

Figura 1. Mapa de localización de las Unidades Territoriales de la Región del Alto Segre. Fuente: Elaboración propia a partir de las bases cartográficas del Departament de Territori i Sostenibilitat. Medi Ambient (2012) y Tulla, 1993.

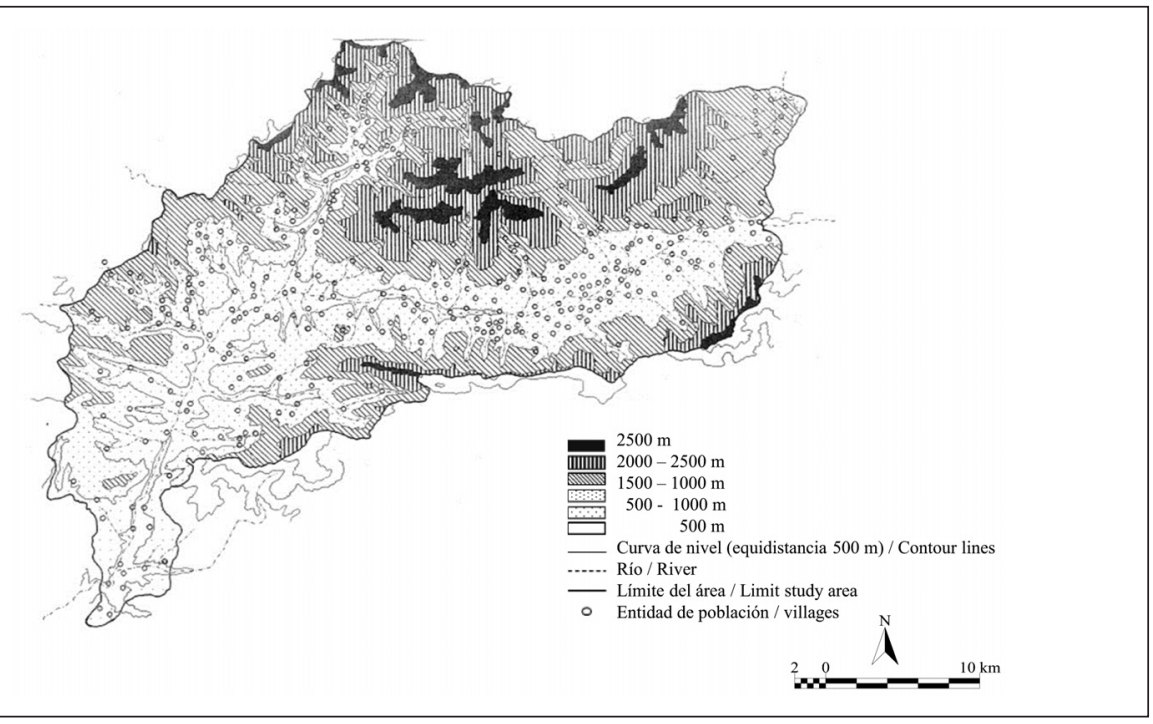

Figura 2. Mapa de la Cuenca hidrográfica del Alto Segre, localización altimétrica y núcleos de población. 
Tratados de Bayona (1866-1868), no se definiría con precisión la frontera franco-hispana. En esta división la comarca histórica de la Cerdanya quedó repartida entre territorio español y francés. La parte francesa, conocida por Alta Cerdanya, pertenece al departamento "Pyrénées-Orientales" de la región administrativa de "Languedoc-Rosellón" (Sahlins, 1989). El tercer límite administrativo se implanta a partir de la división provincial española de 1834, que incluye el territorio del Alt Urgell y una parte de la Baixa Cerdanya en la provincia de Lleida y el resto de la Baixa Cerdanya en la provincia de Girona (Burgueño, 1995). (Figura 3).

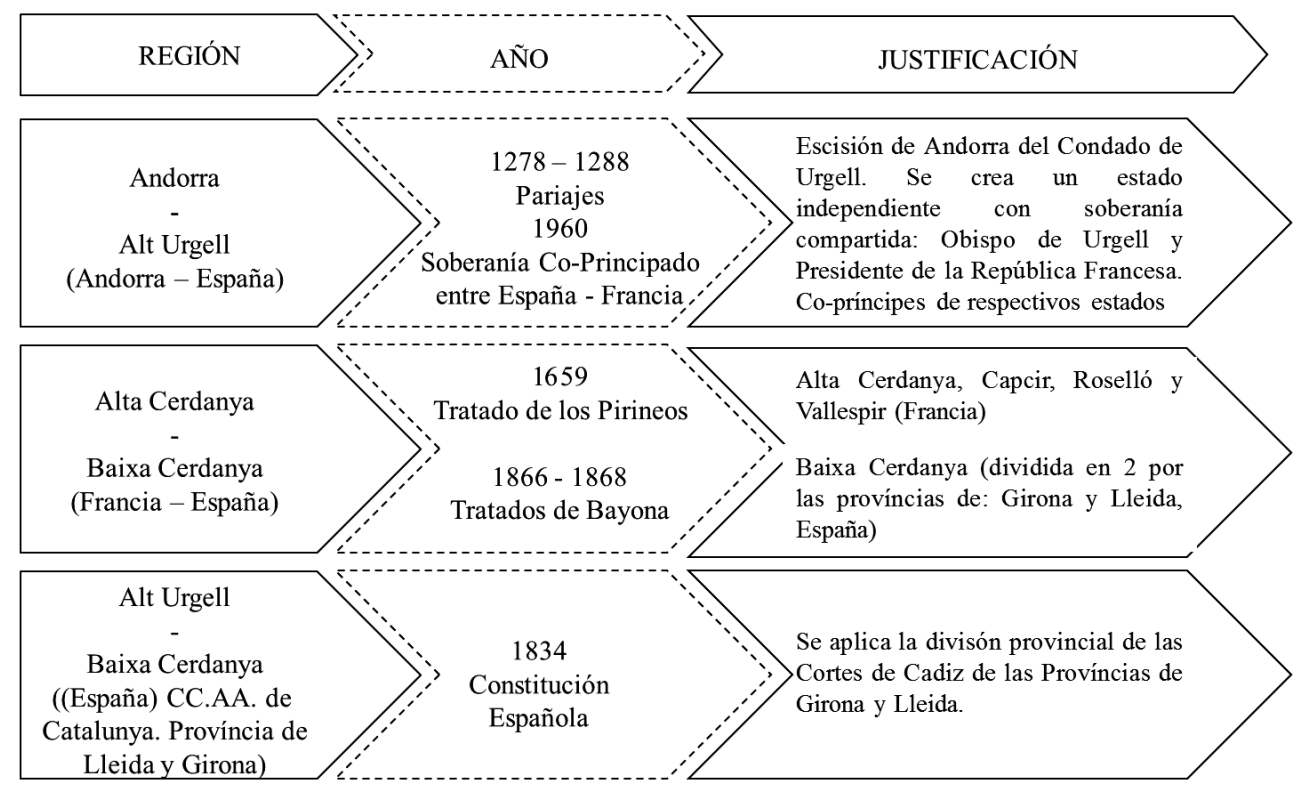

Figura 3. Proceso de separación de las cuatro Unidades Territoriales.

Los Pirineos son un territorio de una economía secular de base pastoril, con un substrato cultural en el que, la casa era el sistema básico de organización económica y social. Estos dos elementos junto con la existencia de un utillaje común permiten identificar la existencia de una cultura pirenaica específica (Comas d'Argemir, 1995). Hasta el siglo XX la economía es básicamente de subsistencia, y autoconsumo (Bricall, 1975; Arqué, 1982; Tulla, 1993). Las principales poblaciones de la región eran importantes centros de mercado de ganado y animales de carga (Puigcerdà, Seu d'Urgell, Bellver y Organyà). La disponibilidad de minas de hierro, madera y ríos permitió el desarrollo de fraguas, talleres textiles, y centrales hidroeléctricas (XII-XIX). Las condiciones orográficas y climatológicas, así como las largas distancias entre núcleos de población, la ausencia de grandes centros urbanos, salvo Andorra desde 1970, el escaso desarrollo de las in- 
fraestructuras de comunicación y la lejanía con las grandes ciudades, conforman un territorio que puede considerarse periférico en su mayor parte. Los principales núcleos de poblamiento se concentran actualmente en el fondo de los valles. En las zonas de mayor altitud, los efectos del despoblamiento se reflejan en el abandono de los pueblos y de las actividades agrarias. En los últimos diez años se ha producido en algunas áreas, una cierta recuperación de la población por inmigración. Sin embargo, es más significativa la residencia estacional o temporal aspecto que está relacionado con la nueva ruralidad y los procesos de naturbanización (Pallarès-Blanch et al., 2014 en prensa).

\section{Análisis demográfico, espacial y socioeconómico e identificación de los flujos en la Región del Alto Segre}

Para el análisis del caso de estudio se recogen como variables principales la evolución demográfica, la concentración espacial relativa y la ocupación económica. Posteriormente, analizamos en el marco de integración y cooperación que permite la UE, los cambios socioeconómicos, y los condicionantes histórico-culturales.

\subsection{Evolución demográfica}

En 1787, primer censo disponible, las cuatro unidades territoriales tienen tamaños de población parecidos, salvo Alt Urgell, que tiene una población algo mayor, en correspondencia con su mayor superficie (Figura 4). A la inversa, Andorra es la que tiene una menor población, en correspondencia con su menor superficie. En esa época Andorra tiene una economía de subsistencia que empuja a gran parte de su población a emigrar. Esta distribución de la población entre las unidades territoriales se mantiene, a grandes rasgos, hasta la segunda mitad del XX.

A partir de los años cincuenta del XX hay un cambio en la estructura demográfica causada por los movimientos migratorios en la zona (inmigración y emigración) resultando en dos procesos inversos. Por un lado, Andorra inicia un fuerte crecimiento demográfico consecuencia de la inmigración atraída por la oferta de empleo que genera su expansión comercial, que es favorecida por el diferencial de precios con España, y por las ventajas fiscales con respecto a España y Francia. A partir de los años ochenta Andorra se especializa en el turismo de nieve, consolidándose el binomio comercio-turismo, que hasta 2005 no había experimentado signos de recesión. En 2011, la población de Andorra concentra el 58\% de la población de toda la región, un tamaño 12 veces superior al de 1787 (Figura 5). Por otro lado, Alt Urgell, Baixa Cerdanya (en España) y Alta Cerdanya (en Francia), comarcas de marcado carácter rural, pierden efectivos por la emigración causada por la escasa competitividad de la agricultura y por- 
que no llegó a producirse un proceso de industrialización moderna. La condición geográfica de región de montaña muestra aquí, claramente, su doble vertiente, presentando limitaciones para la expansión industrial, y ofreciendo, al mismo tiempo, atractivos para el desarrollo turístico, intensamente explotado en el caso de Andorra. A partir del año 2000, Alt Urgell, Baixa Cerdanya y Alta Cerdanya recuperan parte de su población a raíz de la inmigración de procedencia extracomunitaria, que se emplea en el creciente sector de los servicios, especialmente en atención a las personas mayores, hostelería y construcción.

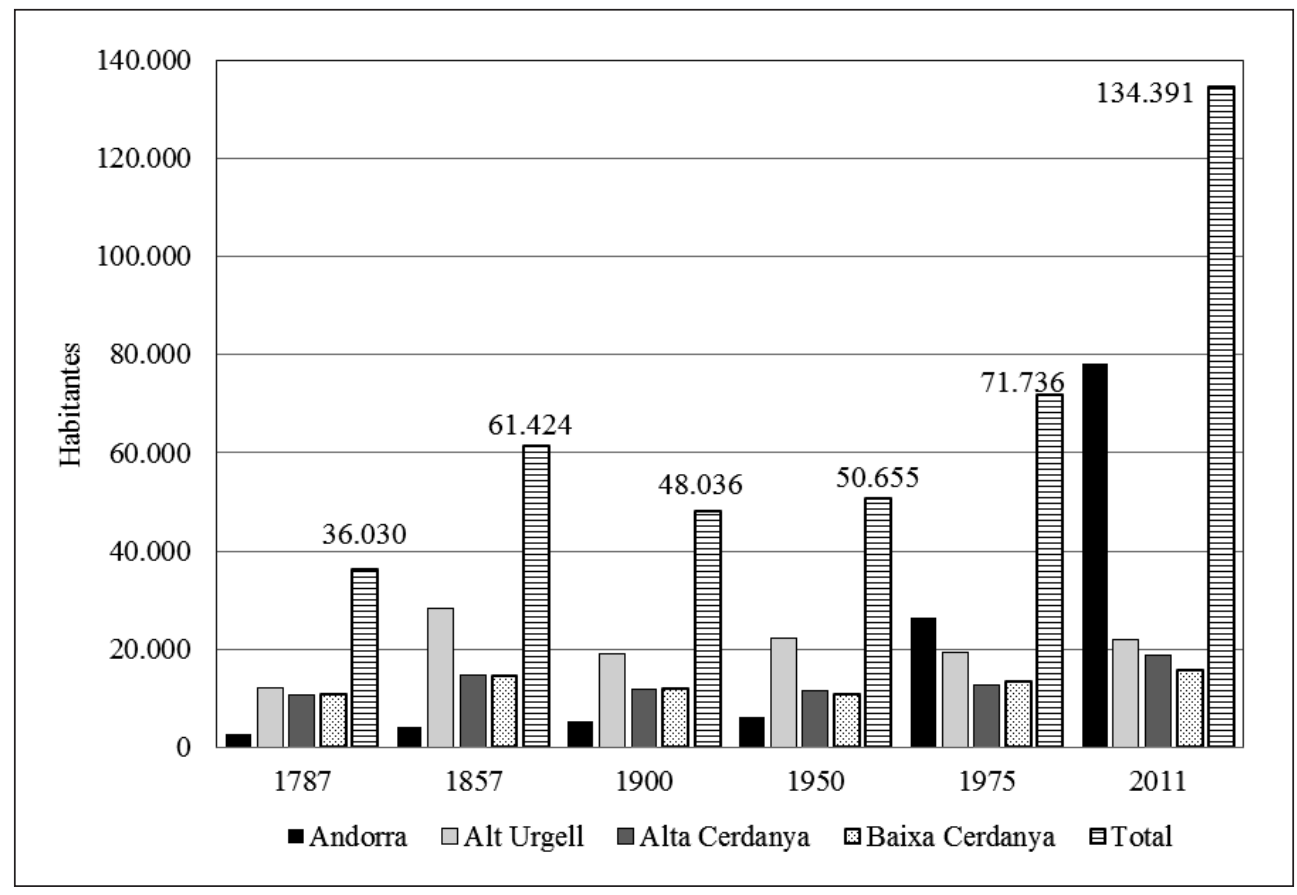

Figura 4. Población absoluta 1978-2011.

Fuente: www.idescat.cat, www.estadistica.ad, www.insee.fr/fr

\subsection{Análisis de la concentración espacial relativa a través de la Curva de Lorenz}

La curva de Lorenz nos indica la concentración espacial relativa (Smith, 1975) de la población en relación con la superficie de cada unidad territorial (Figura 6). Las curvas que están por encima de la línea recta de equidistribución, indican una fuerte disparidad entre el porcentaje de población y el porcentaje de superficie de los cuatro territorios. Este es el caso en Alt Urgell, Baixa Cerdanya y Alta Cerdanya a partir de 1975. 
Las curvas que están por debajo de la diagonal, indican, por el contrario, un porcentaje de población superior al del de la superficie. Estos son los casos de Baixa Cerdanya, más moderado, y muy especialmente de Andorra. La Figura 5, donde también se han incluido los porcentajes de la superficie, permite ver la diferenciación territorial al contrastar su "cuota" de población con la de la superficie, que no se ha modificado durante estos años.

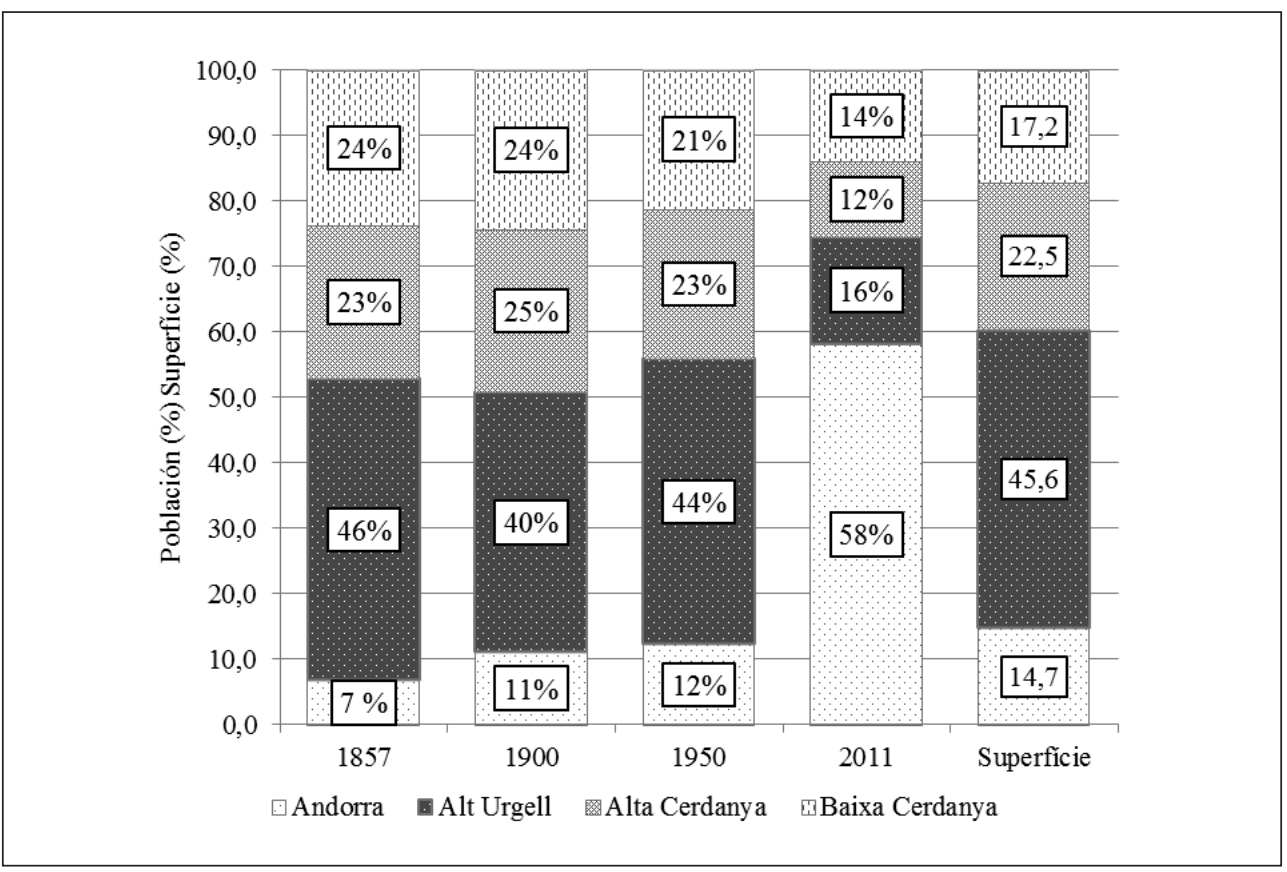

Figura 5. Distribución de la población total en las 4 áreas de estudio, 1857, 1900, 1950 y 2011 y la superficie total.

Fuente: www.idescat.cat, www.estadistica.ad, www.insee.fr/fr

El índice de Gini (IG), es un coeficiente expresado en porcentaje que mide el grado de desigualdad, en este caso, entre la distribución de la población y de la superficie de las cuatro áreas analizadas. Se expresa de forma gráfica mediante las curvas de Lorenz. La Figura 7 señala un aumento de la concentración espacial de la población, que implica un mayor desequilibrio territorial entre las cuatro áreas al variar la estructura de su economía a distintos ritmos. En 1787 con un IG = 19,58\%, vemos que Alta Cerdanya y Baixa Cerdanya tenían más población que superficie en términos relativos, mientras que la situación era la inversa en Alt Urgell y Andorra. En los años 1857, 1900 y 1950 las diferencias son tan pequeñas (IG de 8\%, 9,49\% y 5,67\% respectivamente) 


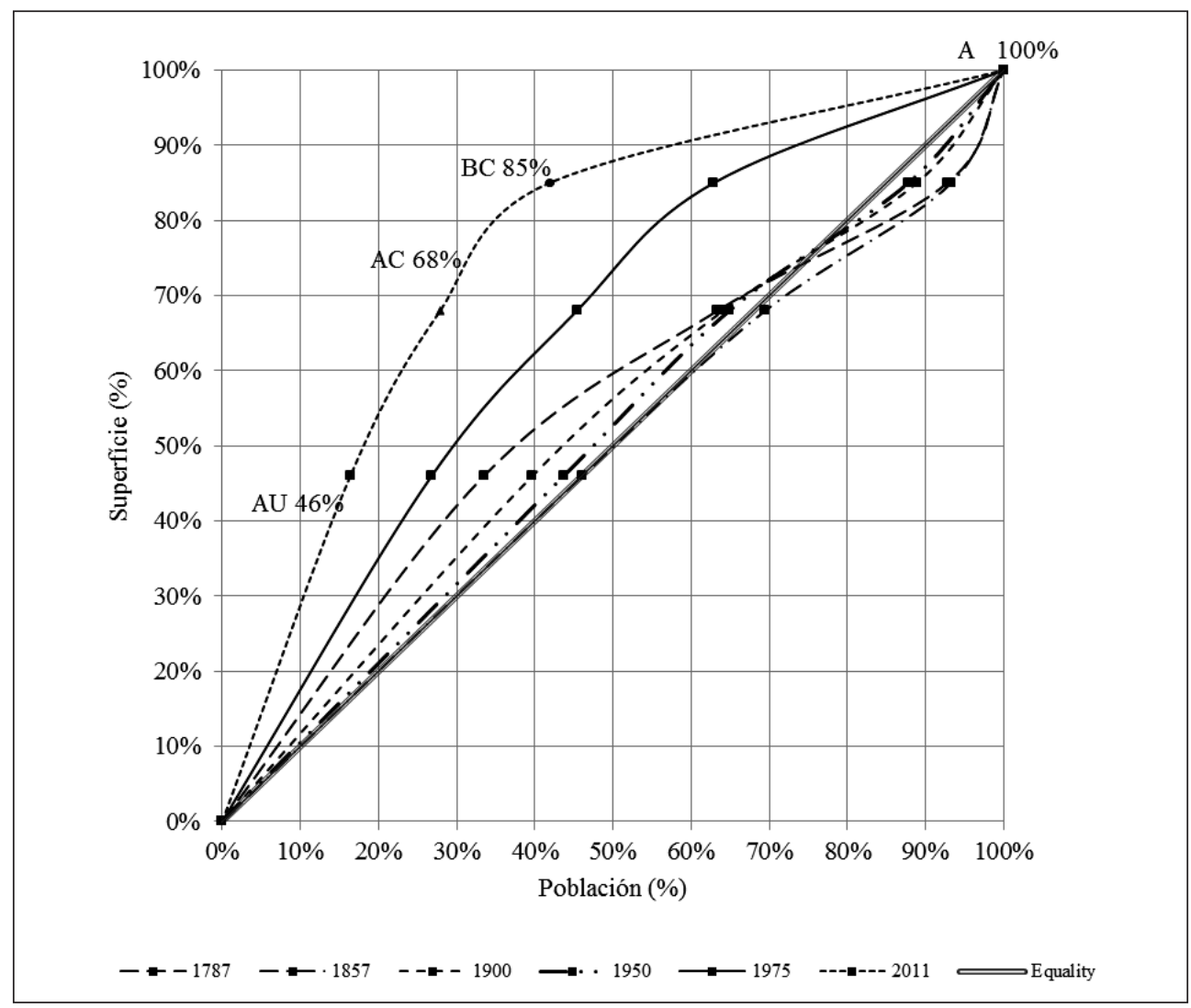

Figura 6. Curva de Lorenz.

Fuente: www.idescat.cat, www.estadistica.ad, www.insee.fr/fr

que puede considerarse que hay una distribución de la población bastante equilibrada con la superficie entre las cuatro áreas y que guarda relación con su capacidad agraria. En el año 1975 (IG = 22,67\%), y de forma más extrema en 2011 (IG = 43,40\%), Andorra tiene 4 veces más población que el que correspondería por el porcentaje de superficie, mientras que Alta y Baixa Cerdanya tienen algo menos de población que de superficie. En cambio, Alt Urgell presenta casi 3 veces menos población que superficie. Este incremento de las desigualdades, como explicaremos a continuación, se debe al crecimiento de la economía de servicios y el turismo especialmente en Andorra y también en Baixa Cerdanya y en Alta Cerdanya versus una economía aún bastante agraria en el caso de Alt Urgell. 


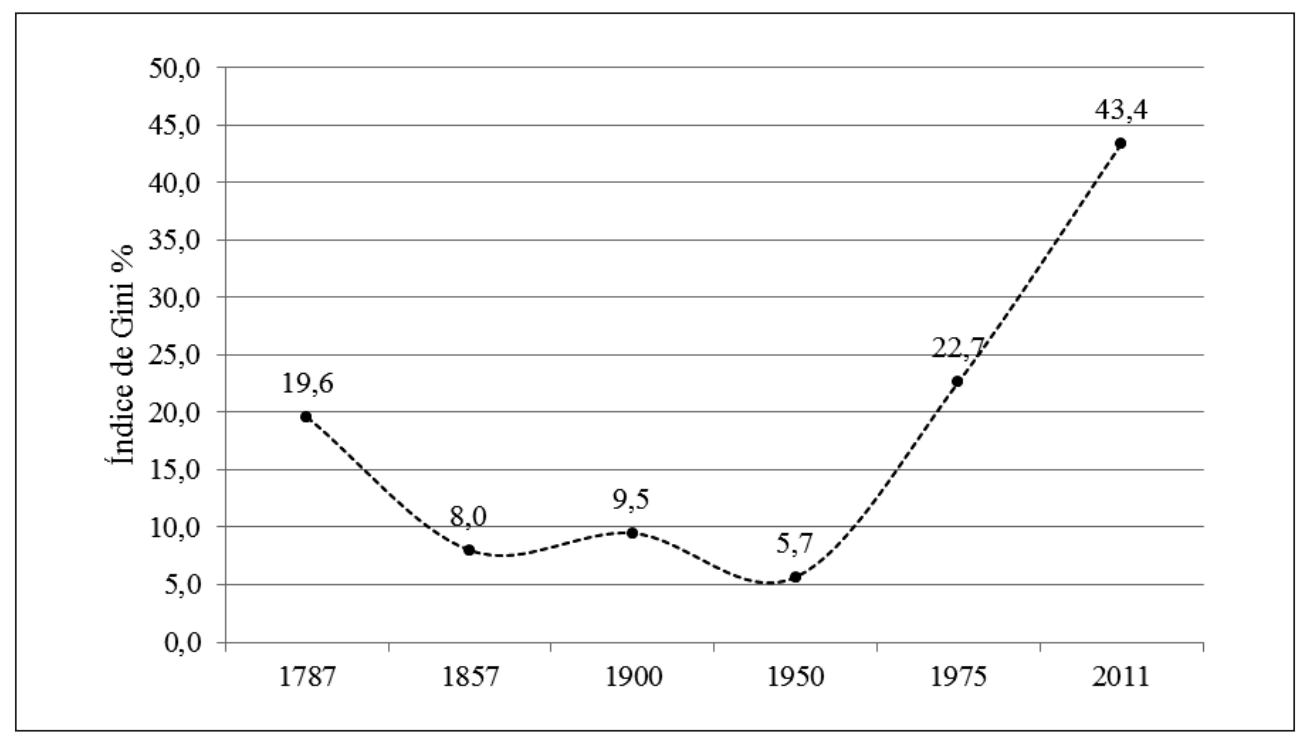

Figura 7. Índices de Gini, 1787-2011.

Fuente: Elaboración propia a partir de www.idescat.cat, www.estadistica.ad, www.insee.fr/fr

\subsection{Especialización productiva}

En 1970 la distribución de la ocupación por sectores de actividad muestra la tendencia de toda la región hacia la especialización en el sector de los servicios, concentrando el 49\% de la población ocupada (Figura 11). La agricultura es aún el segundo sector más importante, con un 24\%. La construcción empieza a ser significativa, ya que con el 16\% de la población ocupada, supera al sector industrial, que cuenta sólo con el 12\%. Analizando por unidades territoriales, observamos cómo, Andorra tiene la mayor concentración de ocupados en los servicios de los cuatro territorios, con el 63\%. En Alta Cerdanya son también importantes los servicios (57\%), aunque se conserva más que en Andorra la ocupación en la agricultura (23\%). Por otro lado, Alt Urgell y Baixa Cerdanya mantienen aún la economía de base agraria, siendo el primer sector en Alt Urgell; 39\% y el segundo en Baixa Cerdanya; 30\%, después de los servicios; 38\% (Figura 8).

En 2001 el proceso de terciarización de la región es muy evidente y se polarizan los dos modelos; por un lado, el de una economía algo más equilibrada entre sectores por parte de Alt Urgell y Baixa Cerdanya y, por otro, el de una mayor especialización en los servicios por parte de Andorra y Alta Cerdanya (Figura 9).

Entre 2001 y 2011 (Figura 10) siguen aumentando los servicios en detrimento de la agricultura, de la industria, y también de la construcción a raíz de la crisis de la bur- 


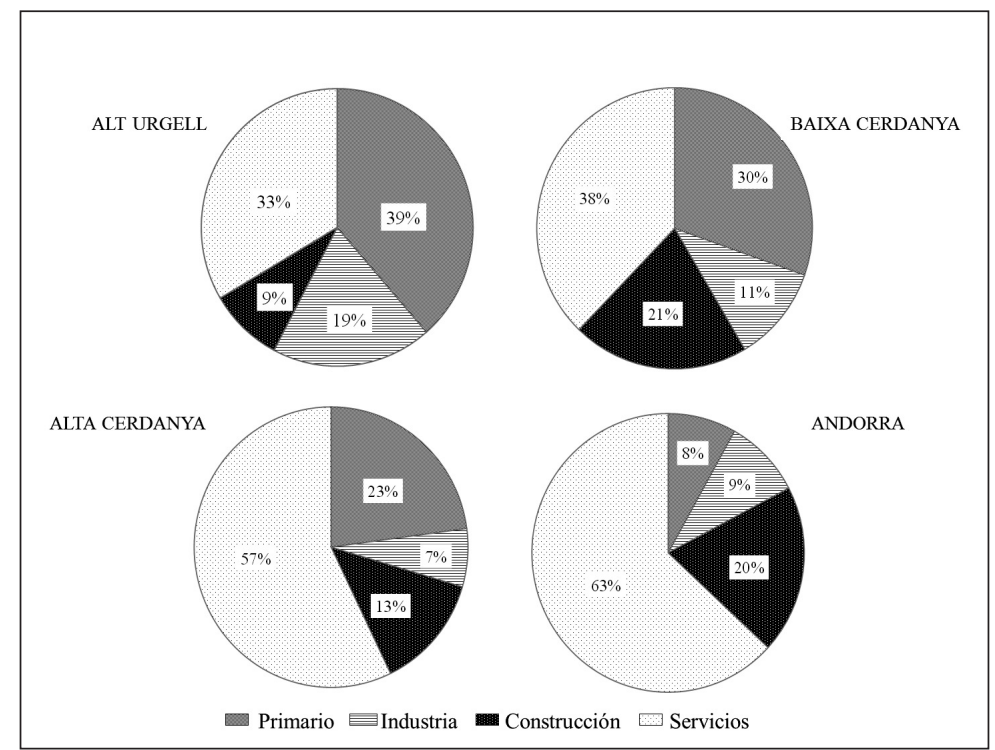

Figura 8. Ocupación por sectores en las cuatro áreas, 1970.

Fuente: www.idescat.cat, www.estadistica.ad, www.insee.fr/fr

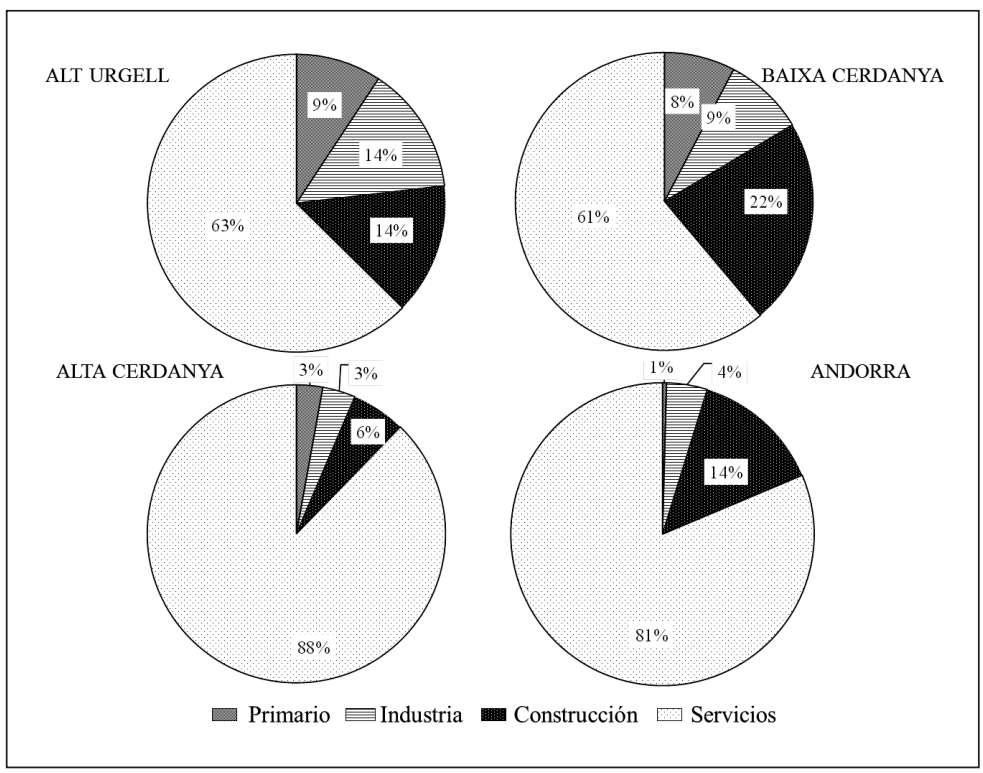

Figura 9. Ocupación por sectores en las cuatro áreas, 2001. Fuente: www.idescat.cat, www.estadistica.ad, www.insee.fr/fr 


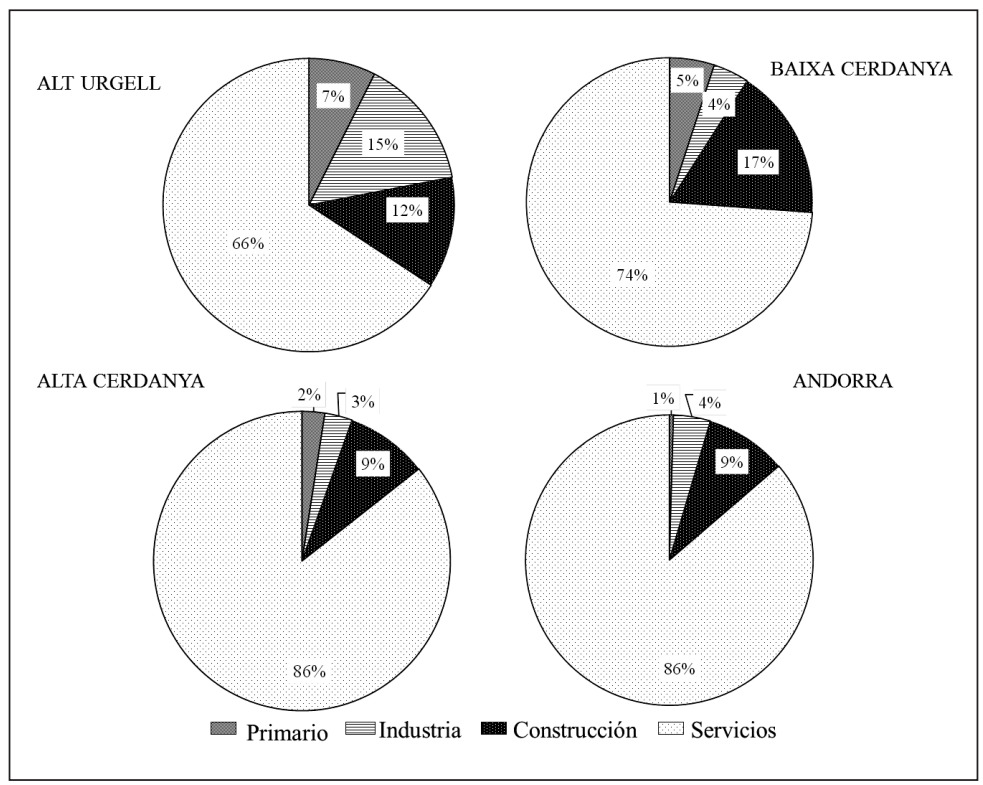

Figura 10. Ocupación por sectores en las cuatro áreas, 2011.

Fuente: www.idescat.cat, www.estadistica.ad, www.insee.fr/fr

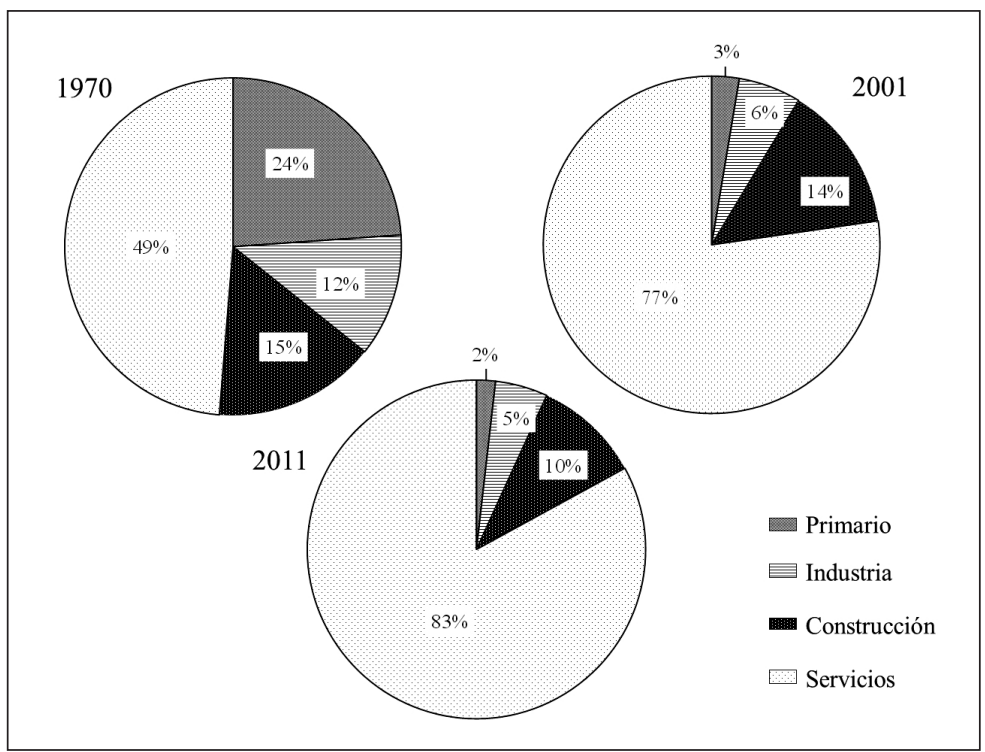

Figura 11. Ocupación por sectores de toda la región, 1970, 2001 y 2011.

Fuente: www.idescat.cat, www.estadistica.ad, www.insee.fr/fr 
buja inmobiliaria (Bernardos Domínguez, 2009; Barrachina y Tulla, 2010). La única área que conserva vestigios del modelo agrario es Alt Urgell. Si comparamos el período entre 1970 y 2011 para toda la región (Figura 11) se puede comprobar de forma clara este aumento del sector terciario desde el 49\% al 83\%, con una reducción moderada de la construcción (del 15 al 10\%) y muy acusada del sector primario (del 24 al 2\%) y de la industria (del 12 al 5\%).

\subsection{Identificación de flujos y condicionantes histórico-culturales entre las cuatro áreas}

En este subapartado ofrecemos una descripción de los principales rasgos históricoculturales relacionados con la especialización económica de cada área.

\subsubsection{Alt Urgell (provincia de Lleida, Reino de España)}

Destacado centro de poder feudal (VIII-XV) por ser, La Seu d'Urgell, actual capital de la comarca, sede del Condado de Urgell, y del Condado de Cerdanya (VIII-IX). El cultivo de vid y olivo, dominante durante siglos, se sustituye a principios del XX por el cultivo de forraje para vacas de leche. Dicha especialización responde a la fundación de una cooperativa lechera productora de mantequilla y queso, la Cooperativa Cadí (en adelante Coop. Cadí) (Gascón, 2010; Gascón, 2009; Tulla, 1993; Mármol del et al. No publicado). Alt Urgell es la unidad territorial de la región que conserva más actividad agraria, como ya hemos visto en la Figura 10 y que se refleja también con el 5,6\% del sector al PIB comarcal ${ }^{12}$. Se fundamenta en un potente subsector lechero (tercera comarca catalana en volumen de producción, el 10\%) (DPTOP, 2009). En la Tabla 1 observamos el elevado aumento de la producción lechera total de esta área, que pasa de 1.000.000 de litros en 1920, a 9.873.000 en 1950 y a 37.347.000 en 1980 (Tulla, 1993). En 2012 la Coop. Cadí, que absorbe el 90\% del total de lecha producida en la comarca, recoge un total de 63.614 .756 litros, el 77\% de ellos producidos en Alt Urgell ${ }^{13}$. El número de explotaciones agrarias se ha reducido radicalmente, incluyendo las lecheras, que pasan de 485 en 1989 y de 200 en 1999, a 90 en 2012 (Tabla 1). Sin embargo, las explotaciones activas son altamente tecnificadas y profesionalizadas en términos de manejo, selección genética y nutrición. El resultado es un competitivo núcleo lechero o clúster lechero entorno a dos cooperativas; la mencionada Coop. Cadí y la Cooperativa Pirenaica (en adelante Coop. Pirenaica) de servicios agrarios, impulsora del sistema unifeed comunitario

12. Fuente: Anuari Econòmic Comarcal 2007. Caixa de Catalunya.

13. Los datos del número de explotaciones ganaderas proveedoras de leche y del número de litros aportados a la Coop. Cadí para las tres áreas; Alt Urgell, Baixa Cerdanya y Alta Cerdanya para el año 2012 han sido facilitados por la propia cooperativa. 
Tabla 1. Explotaciones agrarias de leche de vaca y producción (miles de litros) por áreas, 1950-2009

\begin{tabular}{|c|c|c|c|c|c|c|c|c|c|c|c|}
\hline \multirow[t]{2}{*}{$A \tilde{n}_{0}$} & \multicolumn{2}{|c|}{ Alt Urgell } & \multicolumn{2}{|c|}{ Alta Cerdanya } & \multicolumn{2}{|c|}{ Andorra } & \multicolumn{2}{|c|}{ Baixa Cerdanya } & \multicolumn{2}{|c|}{ Total } & \multirow{2}{*}{$\begin{array}{l}\text { Litros de } \\
\text { leche/expl. }\end{array}$} \\
\hline & Explot. & Litros & Explot. & Litros & Explot. & Litros & Explot. & Litros & Explot. & Litros & \\
\hline 1950 & 1.373 & $9.872,90$ & 752 & $4.000,90$ & 150 & 446,7 & 827 & $6.093,80$ & 3.102 & $20.414,30$ & 6.581 \\
\hline 1980 & 821 & $37.346,50$ & 152 & $4.363,10$ & 42 & 373,8 & 564 & $29.249,20$ & 1.579 & $71.332,60$ & 45.176 \\
\hline 1989 & 485 & - & - & - & - & - & 348 & - & $833^{*}$ & - & - \\
\hline 1999 & 200 & - & - & - & - & - & 151 & - & $351^{*}$ & - & - \\
\hline 2009 & 90 & $61.969,20$ & 32 & $9.237,00$ & 7 & 577,3 & 69 & $12.123,50$ & 198 & $90.907,00$ & 495.126 \\
\hline
\end{tabular}

Explot.: Número de explotaciones agrarias lecheras. Litros: Litros de leche producida.

* Solo las comarcas del Alt Urgell y Baixa Cerdanya.

Fuentes: Censos agrarios de 1989, 1999 y 2009 - Idescat; Tulla (1993); Banc de dades cabana ramadera (2012) -Departament d'Estadística (Govern d'Andorra); Exploitations agrícoles (2011)- INSEE.

por just-in-time (alimentación del bovino lechero especializada y administrada a demanda de las explotaciones). Las sinergias de cooperación entre ambas cooperativas han permitido innovaciones y las mejoras tecnológicas mencionadas (DPTOP, 2009).

Por otro lado la producción agroalimentaria de tipo artesanal y con calidad diferenciada es también importante, registrándose un número similar al de Baixa Cerdanya de establecimientos de producción, elaboración o transformación ${ }^{14}$.

Dentro del sector industrial destacan dos grandes fábricas: la mencionada Cooperativa de productos lácteos y una empresa de fabricación de electrodomésticos, entre otras industrias de valor añadido (taller de diseño de ropa técnica, planta de tratamiento y envasado de agua mineral). Actualmente, La Seu d'Urgell es un centro de servicios públicos y administrativos. Algunos de ellos son delegaciones del gobierno español y catalán ubicadas por la lejanía a los grandes centros urbanos. Otros, son servicios específicos fijados por la presencia de la frontera con Andorra (Policía Nacional), que en parte vienen determinados por limitar con un Estado no comunitario (servicios de Aduanas). Otros servicios atienden las necesidades creadas por los flujos transfronterizos como servicios

14. Se contabilizan cuarentaiún establecimientos de producción, elaboración o transformación de productos agroalimentarios (carne de bovino ecológica, carne de ovino, hortícolas y frutícolas ecológicas, quesos y otros lácteos artesanales, mermeladas y salsas artesanales, pan y bollería artesanal, miel artesanal, vino artesanos, cerveza artesana, embutidos y productos cárnicos artesanales, productos medicinales naturales). Tres de los cuarentaiún con certificado de producción ecológica, once de los cuarentaiún con distintivo de productos de proximidad, Fuente: Base de datos del Centre de Desenvolupament Rural Integrat de Catalunya (CEDRICAT). 
de transporte o de mensajería (Pallarès-Blanch y Tulla, 2011). La situación de paraíso fiscal de Andorra, hasta 2010 para la UE, y su menor fiscalidad propician determinadas prácticas ilegales (contrabando y evasión de capital). Actualmente es la comarca de Alt Urgell la que mantiene una relación de dependencia con Andorra, en tanto que centro proveedor de empleo y de servicios comerciales (Margarit, 2012). Por esta vecindad, Alt Urgell también recibe nuevos residentes procedentes de Andorra atraídos por los inferiores precios de la vivienda. La mayor disponibilidad de suelo útil de Alt Urgell con respecto a Andorra es el motivo por el cual existen inversiones privadas andorranas en esta área, como son ejemplos un campo de fútbol en Alàs y el campo de golf "Aravell Golf Andorra" promovido por una empresa pública comarcal y un grupo de inversores andorranos. La cooperación institucional en infraestructuras compartidas es aún incipiente, aunque existen negociaciones para la participación andorrana en el futuro aeropuerto de La Seu d'Urgell, cuyo funcionamiento se prevé para 2015. En el Aeropuerto de Alguaire-Pirineus, cerca de Lleida capital, operan compañías que transportan pasajeros con destino a las estaciones de esquí del Pirineo, entre ellas las de Andorra.

En la relación de Alt Urgell con Andorra se identifican, en los estudios llevados a cabo por Pallarès-Blanch y Tulla (2011) y Pallarès-Blanch et al. (2005), tres factores clave. En primer lugar, una elevada intensidad de flujos de personas, compras y capital que permite explicarla como una región de economía de frontera. En segundo lugar, se detecta que, además de las diferencias de precios, existen otros factores determinantes en la interacción de flujos, como la elevada oferta de trabajo en Andorra, hasta fechas recientes. En tercer lugar, son los vínculos familiares y personales entre ambos lados de la frontera, los que favorecen la interrelación, añadiendo confianza, sobre todo en las transacciones comerciales, de modo que puede hablarse de relaciones de lealtad territorial (Pallarès-Barberà et al., 2004).

\subsubsection{Alta Cerdanya (République française)}

La evolución de su población se caracteriza por dos factores: el envejecimiento de la población, y las emigraciones, en dirección al sur de Francia (desde el s. XVIII) y hacia el Área Metropolitana de Barcelona (AMB) (s. XX) (Moncusí, 2004; Tulla 1997; Vila 1926). Las comunicaciones modernas llegan en el XIX -carreteras- y en el XX -ferrocarril desde Toulouse (1929) y desde Perpignan (1914)- (Vila, 1926; Tulla 1977). El primer hotel y estación de esquí se construye en 1912 en Font Romeu, siendo el área de la región de más temprana urbanización. Las escasas industrias son tres hornos solares y los servicios de salud (balnearios y clínicas). En la última década del XX se incrementan las segundas residencias ${ }^{15}$ de población procedente principalmente del AMB

15. Información procedente de las consultas realizadas a los agentes locales citados en la metodología. También son fuentes de información las consultas a la hemeroteca. Seleccionamos tres de ellas: 
y de ciudades del sur de Francia como Toulouse y Perpinyà. El turismo cultural está relacionado con el legado arquitectónico medieval, cuando la Alta Cerdanya pertenecía al condado de Cerdanya, por lo que conserva valor emblemático para la identidad catalana, junto a elementos de su patrimonio natural. La cultura catalana es reclamo turístico en todo el departamento de los Pyrénées Orientales (comida, folklore, suvenires etc.) promocionada bajo la marca turística "Pays catalan". La falta de inversiones públicas del Gobierno francés en el sur de Francia genera críticas al modelo centralista del Estado francés (Clout, 1986; Flockton et al., 1989).

La producción ganadera tiene una importancia relativa, tal como se puede ver en la Tabla 1. Hasta 1950 había 752 explotaciones productoras de leche que han quedado reducidas únicamente a 32 en 2009, pero duplicando el volumen de producción. La mayor parte de explotaciones aportan la leche a la Coop. Cadí, reforzando el clúster de transformación de lácteos de Alt Urgell, Alta Cerdanya y Baixa Cerdanya.

En los últimos años y especialmente entre la población joven, crecen las iniciativas de cooperación cultural y artística con Cataluña, que cuentan con el apoyo del Gobierno Catalán en el fomento de las relaciones entre los Países Catalanes ${ }^{16}$. En la localidad de Prada de Conflent se celebra anualmente desde 1968 la Universidad Catalana de Verano que congrega asistentes de todas partes de los Países Catalanes. Alta Cerdanya tiene una distribución de la ocupación terciarizada, similar a la de Andorra, pero desde 1950 su población ha perdido peso relativo en la región, del 25\% al 12\% en 2011 (Figura 5). Los servicios que se desarrollan están relacionados con la administración y el turismo de nieve,

1) Noticia del 8-12-12 en el diario Periódico de Cataluña (edición en línea en catalán) sobre la ley antifraude (Ley 7/2012, de 29 de octubre, de modificación de la normativa tributaria y presupuestaria y de adecuación de la normativa financiera para la intensificación de las actuaciones en la prevención y lucha contra el fraude). Se informa que Hacienda fuerza a declarar bienes y pisos en el extranjero. Los españoles con casas en Andorra o en el sur de Francia, entre los más afectados. http://www.elperiodico.cat/ca/noticias/economia/hisenda-forca-declarar-bens-pisos-lestranger-2267921

2) Noticia del 18-10-12 en el diario comarcal Regió 7, sobre la apertura de una Escuela Oficial de Idiomas en Puigcerdà. Se valora el servicio de idiomas para la consolidación del turismo de corta estancia como pilar económico y del francés, en particular, idioma oficial de la mitad de los "cerdans" y por tanto necesario para la proyección y redefinición de los lazos históricos con Alta Cerdanya. "Su papel, en la promoción hacia el norte del deseado turismo unificado del valle, será clave para la nueva marca y la nueva manera de hacer, más global". http://www.regio7.cat/opinio/2012/09/18/cerdanya-que-parla-al-mon/210113.html

3) Noticia del 21-01-91 recogida en Euscreen (base de datos audiovisuales televisados en Europa). Se define como "auténtico boom inmobiliario" el que está aconteciendo en Alta Cerdanya por parte de barceloneses que adquieren viviendas para segunda residencia. Se vincula el fenómeno a tres factores clave; la apertura del Túnel del Cadí (1983), la precios más bajos en territorio francés, que no habrían recibido el efecto de la especulación y los prestamos hipotecarios más baratos que en territorio español (11\% de interés de media). Un ejemplo es el pueblo de Bajande, en el que 24 de las 25 nuevas viviendas proyectadas se habían vendido a catalanes. El fenómeno es generalizado, se informaba, en todas las regiones francesas que limitan con el Estado Español. http://euscreen.eu/play.jsp?id=EUS_02C92B37B77C41D8823CD0EE3B8016D8

16. Països Catalans (Países Catalanes) hace referencia a los territorios donde la lengua autóctona es el catalán y que forman parte de unidades geo-históricas de predominio lingüístico catalán. 
de descanso y de salud. El envejecimiento de la población, solo se ve compensado por la población estacional. El alto precio de la vivienda en España ha llevado a que sea una opción de residencia permanente para algunas personas del lado español de la frontera, situación que se hizo evidente a partir de 1986 porque en Baixa Cerdanya la fuerte demanda de suelo para nuevas urbanizaciones había hecho aumentar los precios de las residencias, tanto permanentes como temporales (Moncusí, 2004). La actividad agraria es minoritaria, pero ofrece productos de alta calidad. Cuenta con jóvenes emprendedores, especialmente activos en la promoción de una agricultura de organización cooperativista que fomenta el consumo de proximidad y de corto circuito (Suné, 2012).

\subsubsection{Andorra (Principat d'Andorra)}

Hasta mediados del s. XX Andorra mantiene una alta dependencia con la ciudad vecina española, La Seu d'Urgell, donde se encuentra la sede del Obispado de Urgell y, por lo tanto, sede también de uno de los Copríncipes del gobierno de Andorra ${ }^{17}$. El cultivo del tabaco, iniciado en el s. XVII, tuvo gran éxito durante la I y la II Guerras Mundiales. La energía hidroeléctrica vendida a Francia y España desde 1932, permitió obtener capital para las primeras inversiones turísticas. La apertura de la carretera del Pas de la Casa, en 1933, fue la primera infraestructura importante. A partir de los años sesenta del siglo XX se produce el boom del consumo y el aumento del turismo internacional, coincidiendo con los inicios del crecimiento económico en España y con la consolidación económica de Francia. La necesidad de organización del país lleva a la aprobación de la Constitución Andorrana en 1993, con la consecuente entrada en la ONU. La firma de acuerdos ${ }^{18}$ con la Unión Europea se produce a partir de 1991 (Pou,

17. El régimen de coprincipado es el resultado del sistema de gobierno con el que Andorra se independizó del Condado de Urgell, en 1278. Hasta 1993 Andorra estuvo gobernada per dos señores feudales; el obispo de Urgell y los herederos del título del condado de Foix, que acabó perteneciendo a la Corona de Francia y después a la República Francesa. Los dos representantes del coprincipado actual son; per un lado, el obispo de Urgell, con sede a la ciudad vecina de La Seu d'Urgell (Alt Urgell), situada en territorio catalano-español, y por otro lado, el presidente de la República Francesa. La Constitución de 1993 concede un papel más importante al Gobierno y con ella se formalizan las relaciones de buena vecindad con los estados vecinos. http://www.boe.es/boe/dias/1993/06/30/pdfs/A19876-19877.pdf. [Consulta: 22-04-13].

18. Andorra mantiene un acuerdo de unión aduanera con la UE desde 1991 que abarca los bienes industriales y su protocolo sobre medidas aduaneras de seguridad. El 2004 se establece un marco para la cooperación en materias de medio ambiente, educación, transporte, cultura, política regional y cuestiones veterinarias. Desde 2005 se disponen acuerdos en materia de fiscalidad del ahorro. Desde 2011 Andorra puede acuñar monedas de euro, usada de facto desde la introducción de la moneda. En 2010, el Consejo de la UE solicitó un análisis de las posibilidades de integrar Andorra, Mónaco y San Marino en el mercado único. Andorra también coopera en representaciones diplomáticas en las principales organizaciones internacionales (Nueva York, Ginebra, Viena y Estrasburgo), con el fin de intercambiar información y coordinar posiciones en materia de seguridad exterior y en derechos humanos. http://ec.europa.eu/world/agreements/ y http://register.consilium.europa.eu/pdf [Consultas 26-03-13]. 
1994; Bricall, 2001; Lluelles, 2007). También desde los años noventa del s. XX se desarrollan acuerdos en materia educativa ${ }^{19}$, sanitaria ${ }^{20}$, medioambiental ${ }^{21}$ y de transparencia económica ${ }^{22}$ y la Generalitat de Catalunya, que afectan especialmente a la comarca vecina de Alt Urgell. Andorra representa en estos momentos el centro financiero, comercial, urbano y turístico más importante de los Pirineos. Ni el sector industrial ni el de la construcción son significativos, y el agrario es prácticamente inexistente (Figura 10 y Tabla 1). Las relaciones de complementariedad más intensas se dan con Alt Urgell. Estas interacciones fueron estimadas en Pallarès-Blanch et al. (2005) a partir de tres flujos principales de capital: 1) el flujo monetario de los sueldos ${ }^{23}$ transfronterizos $^{24}$ la Seu d'Urgell-Andorra, el 6\% de la fuerza de trabajo andorrana en 2005 ${ }^{25}$, (38.743.483,18 euros en 2005), 2) el flujo de capital por adquisición de bienes muebles (34.772.079 euros de 2003); el 10\% de clientes y el 27\% de las ventas en la Seu d'Urgell, junto a 16.000.000 euros de exportaciones de la Seu d'Urgell a Andorra ${ }^{26}$ y 3) las transferencias de capital para la adquisición de bienes inmuebles con 1.373 de propiedades adquiridas por andorranos desde el año 1993 al $2002^{27}$ con un valor de 121.955 .353 euros en

19. Convenio de ordenación y adaptación al sistema educativo español. http://www.boe.es/boe/dias/ 2005/03/22/pdfs/A09751-09756.pdf [Consultado: 22-04-13]. En Andorra existe la "escuela andorrana" en catalán, la "escuela española", en español y la escuela francesa", en francés.

20. Acuerdo de 9 de noviembre de 2001 entre el Gobierno de Andorra y el de España y acuerdo de 3 de setiembre de 2010 entre el Gobierno Catalán y el Principado de Andorra en materia de asistencia sanitaria. El convenio regula las relaciones en el área de la Seguridad Social, dadas las reformas introducidas en los sistemas de los dos Estado desde la conclusión del Convenio Hispano-Andorrano de Seguridad Social de 14 de abril de 1978 y es de aplicación a los trabajadores que estén o hayan estado sujetos a las legislaciones de Seguridad Social de una o ambas Partes Contratantes, así como a los miembros de sus familias y supervivientes. http://www.boe.es/boe/dias/2002/12/04/pdfs/A42279-42287.pdf y http://www20.gencat.cat/portal/site/portaldogc http://www.seg-social.es/Internet_1/Normativa/095129\#documentoPDF [Consultas: 22-04-13].

21. Acuerdo de 27 de enero de 2000 por el que se dispone la remisión a las Cortes Generales del Acuerdo entre el Reino de España y Andorra sobre el traslado y gestión de residuos. http://www.boe.es/diario_boe/ txt.php?id=BOE-A-2000-4695 [Consultado: 22-04-13].

22. Acuerdo de 26 de marzo de 2010 entre el Reino de España y Andorra para el intercambio de información en materia fiscal como medida para excluir Andorra de la lista española de paraísos fiscales. http://www.boe.es/boe/dias/2010/11/23/pdfs/BOE-A-2010-17975.pdf y https://www.boe.es/buscar/doc.php? id=BOE-A-1991-18119 [Consultado: 22-04-13].

23. 17.483,83 euros de sueldo medio andorrano con el 5\% de incremento (datos del año 2003).

24. Existe un conocimiento inexacto del número de trabajadores transfronterizos. El estudio Pallarès-Blanch et al. (2005) realiza los cálculos de estimación del impacto económico de los flujos entre Andorra y Alt Urgell a partir de 1.527 (cálculo estimativo a partir de datos de la Caixa Andorrana de Seguridad Social -CASS). Un estudio más reciente contabiliza 2.357 trabajadores transfronterizos de España a Andorra en el año 2007. Fuente: Departament d'Immigració del Govern Andorrà (Margarit, 2012).

25. La población ocupada en Andorra en 2005 era de 52.000 personas.

26. Ponderación hecha a partir de 1.000 permisos de declaración de exportación diaria de España en Andorra (Fuente: Elaboración propia con datos facilitados por la Aduana Española en la Farga de Moles). 1.094.688.447 euros por toda España. Valor económico de 2002.

27. Información procedente de archivos municipales del área de estudio seleccionada (Pallarès-Blanch et al., 2005). 
propiedades urbanas y rústicas procedentes de capital andorrano, junto con 1.425 .150 euros de capital andorrano a 1.202 euros $/ \mathrm{m}^{2}$ en parcelas en polígonos industriales del Alt Urgell, con un 50\% de superficie construida estimado en 3.562.728 euros (PallarèsBlanch et al., 2005).

\subsubsection{Baixa Cerdanya (dividida por las provincias de Lleida y Girona en el Reino de España)}

Su capital, Puigcerdà, fue centro de uno de los mercados de ganado más importantes de la región en la Edad Media (Vila, 1926). Desarrolla actividad industrial relacionada con los talleres de textil y lana (XII) e industrias de algodón (XIX-principios del XX, que desapareció al integrarse la región en el mercado global). Actualmente, Puigcerdà, es un centro de mercado tanto para Alta Cerdanya como para Baixa Cerdanya. Las comunicaciones modernas, de inicios del XX (carretera desde Ripoll en 1914 y ferrocarril desde Barcelona en 1922) (Vila, 1926), le permitieron ser el destino turístico de la burguesía catalana y de los primeros esquiadores en la estación de esquí "La Molina" (1908). La apertura del Túnel del Cadí en 1983, acentúa la especialización turística, ofreciendo millares de segundas residencias para la AMB (Moncusí, 2004; Tulla, 1997; DPTOP, 2009). La segunda residencia en Baixa Cerdanya (9.081 unidades de viviendas secundarias, 10.312 si les sumamos las viviendas vacantes) representada el 57,28\% (65,04\% secundarias con vacantes) sobre el total de viviendas (15.855 unidades) del área en 2001. Es deducible, a falta de datos más recientes, que el porcentaje siguió aumentado hasta 2008, puesto que fueron años de gran crecimiento de la construcción. Entre Puigcerdà y la localidad francesa de Bourg-Madame es un continuo urbano. A 6,4 km de Puigcerdà, se localiza el enclave español de Llívia, en territorio francés. Baixa Cerdanya, mantiene algo más de actividad en el sector agrario que Alta Cerdanya (Figura 10) y cuenta también con algunos ejemplos de emprendeduría joven que adoptan el modelo de valor añadido, a base de producción ecológica y de elaboración artesanal de transformados lácteos (queso y yogurt) y de embutidos entre otros productos agroalimentarios ${ }^{28}$ (DPTOP, 2009; Suné, 2012). El sector ganadero de producción de leche tuvo un momento álgido en 1980, pero después ha ido disminuyendo (ver Tabla 1).

28. Se contabilizan cuarenta y seis establecimientos de producción, elaboración o transformación de productos agroalimentarios (carne de bovino ecológica, carne de ovino, hortícolas ecológicas, quesos y otros lácteos artesanales, mermeladas y salsas artesanales, pan y bollería artesanal, miel artesanal, helados naturales, embutidos y productos cárnicos artesanales, productos medicinales naturales). Cinco de los cuarenta y seis con certificado de producción ecológica, quince de los cuarenta y seis con distintivo de productos de proximidad, Fuente: Base de datos del Centre de Desenvolupament Rural Integrat de Catalunya (CEDRICAT). 
Otro elemento diferencial de Baixa Cerdanya respecto a Alta Cerdanya es el elevado peso del sector de la construcción (17\% en 2011), a pesar que se ha reducido respecto el 22\% de 2001. La buena conectividad con los centros urbanos de Catalunya permite a la población mantener empleos fuera de la comarca (Tulla y Pallarès-Blanch, 2008). Las relaciones con Alta Cerdanya han sido y siguen siendo fluidas (Moncusí, 2004). Se realizan algunas celebraciones conjuntas como la Fiesta del Árbol y el Día de la Cerdanya, promovidas desde la asociación cultural Institut d'Estudis Ceretans, con sede en Puigcerdà. En 2006 se crea la Agrupación Europea de Cooperación Territorial (AECT) ${ }^{29}$ "Hospital de la Cerdanya" 30 para el gobierno del Hospital transfronterizo Cerdanya-Capcir, con acuerdos entre la administración sanitaria francesa y la administración sanitaria catalana y con la participación de las administraciones locales y regionales respectivas. En 2012 se crea la AECT "Pirineus-Cerdanya" 31 entre el Consejo Comarcal de Baixa Cerdanya y la Comunidad de Comunas de Alta Cerdanya ${ }^{32}$, para dar forma jurídica a la gestión compartida de un Matadero transfronterizo, la coordinación de la promoción turística y patrimonial, y el impulso de proyectos futuros como un Instituto de Enseñanza Secundaria o la gestión del agua. Otros proyectos de cooperación transfronteriza de menor envergadura, todos financiados por el Programa Interreg, son: un estudio de gestión de las riberas del río Segre entre Alta Cerdanya, Baixa Cerdanya y Alt Urgell (Contrato del Río Segre) y un plan de gestión concertada del río Carol. Otro ejemplo de cooperación entre las dos Cerdanyas, en este caso impulsado por entidades culturales, es la reciente constitución del "Cor Transfronterer de la Cerdanya" con cantores de Alta y Baixa Cerdanya, que actúa junto a la "Orquestra Adagio" con músicos de Andorra y Alt Urgell, y que actuaron por primera vez en la Catedral de Santa Maria d'Urgell el 23 de Febrero de 2013.

La síntesis de los flujos generados entre las cuatro áreas de la Región del Alto Segre puede leerse a modo de esquema en la Figura 12. Debe distinguirse entre los acuerdos transfronterizos más institucionalizados y las relaciones de hecho, documentadas en base a los estudios previos realizados y a las consultas a expertos locales.

29. Reglamento (CE) no 1082/2006 sobre la Agrupación europea de cooperación territorial (AECT) (Beltran, 2010).

30. AECT-10. "Hospital de la Cerdanya". http://www.hcerdanya.eu/webgc/es/qui.html [Consultado: 20-1013]. Fuente: Dirección General de Coordinación de Competencias con las Comunidades Autónomas y las Entidades Locales, 2013.

31. AECT-5. "Pirineos-Cerdanya". Fuente: Dirección General de Coordinación de Competencias con las Comunidades Autónomas y las Entidades Locales, 2013.

32. Communauté de Communes "Pyrénées-Cerdagne". 
- Alumnos de Andorra en centros de enseñanza de La Seu d'Urgell (Alt Urgell).

- Compras de producto fresco de Andorra en el Alt Urgell

- Bienes inmuebles (establecimientos comerciales, industriales y segundas residencias) de Andorra a Alt Urgell.

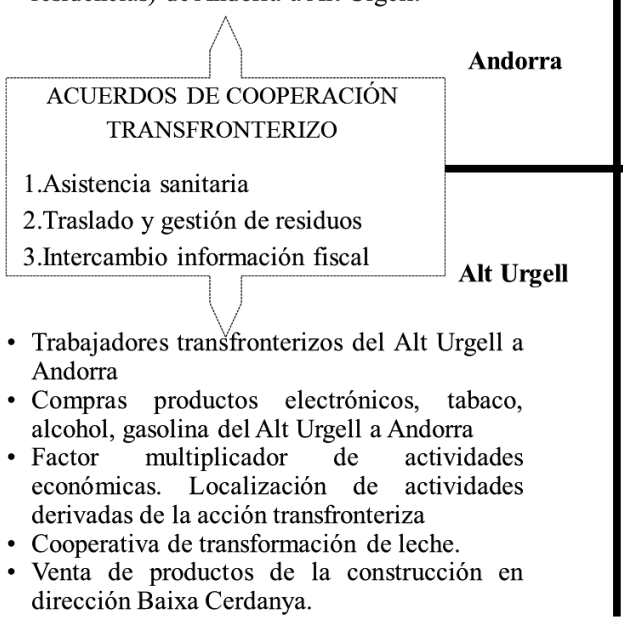

- Compra de bienes e inmuebles; de establecimientos comerciales y de negocios en dirección Andorra i Baixa Cerdanya.

- Flujos migratorios en dirección Andorra y en dirección Baixa Cerdanya.

- Interacciones culturales con Andorra, Baixa Cerdanya i Alt Urgell.

Alta

Cerdanya

ACUERDOS DE COOPERACIÓN TRANSFRONTERIZO

1.Matadero

2.Hospital transfronterizo

Baixa

3.Instituto Enseñanza Secundaria $\mathrm{Ob}$

Cerdanya

- Compras de bienes inmuebles de la Baixa Cerdanya a la Alta Cerdanya

- Turismo en dos sentidos, más de la Baixa Cerdanya a la Alta Cerdanya.

- Compras productos electrónicos, tabaco, alcohol, gasolina de la Baixa Cerdanya a Andorra.

- Venta de leche de vaca a la cooperativa CADI.

- Venta de productos lácteos artesanos

Figura 12. Flujos generados más representativos entre las cuatro áreas de la Región del Alto Segre.

\section{Perspectivas de integración de la Región del Alto Segre}

En el análisis de las interrelaciones transfronterizas entre las cuatro áreas se revelan tres tipos de interacciones diferentes:

Un primer tipo de interacción transfronteriza en esta región se produce entre Andorra y Alt Urgell, con intensos flujos de población por motivos sobretodo laborales y también comerciales, culturales y familiares (Margarit, 2012; Pallarès-Blanch et al., 2005, 2011; Tulla et al., 2007; 2008). El actual contexto de crisis económica, sin embargo, amenaza la continuidad de este modelo de provisión de lugares de trabajo por parte de Andorra a la población de Alt Urgell, teniendo en cuenta que desde 2008 Andorra ofrece pocos permisos de trabajo ${ }^{33}$ y por primera vez el desempleo es significativo.

33. Actualmente se excluye la movilidad de trabajadores transfronterizos, salvo en excepciones justificadas por necesidades empresariales. 
Un segundo tipo de interacción transfronteriza identificado es entre las comarcas catalanas de Alt Urgell y Baixa Cerdanya, y recientemente con Alta Cerdanya, que se desarrolla en torno al clúster económico, basado en la producción y transformación de leche y articulado a través de la Coop. Cadí y la Coop. Pirenaica. Del análisis de los datos de recogida de leche de 2012, facilitados por la Coop. Cadí, para estas tres unidades territoriales, se desprende que se ha consolidado dicho clúster, al pasar de 7.660.000 litros en 1950, a 38.036.000 en 1980 (Tulla, 1993) y a 63.614.756 en 2012. En 2012 son 112 las explotaciones lecheras que aportan a la Coop. Cadí. De estas 112, 62 son explotaciones de vacas lecheras localizadas en Alt Urgell (77,4\% del total procesado por la Coop. Cadí), 27 explotaciones son de Baixa Cerdanya (9,6\% del total procesado) y 23 explotaciones de Alta Cerdanya con el 13\% procesado. Fruto de la coordinación entre ambas cooperativas y gracias a la calidad de los alimentos producidos y elaborados, Alt Urgell cuenta con tres distinciones de calidad ${ }^{34}$, por la mantequilla, el queso y la ternera. En consecuencia, la agricultura de toda la región depende en gran medida de este polo de innovación agro-industrial. Además, la totalidad de los municipios de Alt Urgell junto con cinco municipios de Baixa Cerdanya constituyen el ámbito territorial del Consorcio LEADER de Alt Urgell-Cerdanya, hecho que refuerza la cooperación entre las dos comarcas en materia de desarrollo rural (DPTOP, 2009; Mármol et al., 2011-no publicado).

El tercer tipo de interacción transfronteriza identificado, también trans-estatal, como entre Andorra y Alt Urgell, es en la gestión conjunta de servicios públicos entre Alta Cerdanya (Francia) y Baixa Cerdanya (España): Matadero, Hospital, Instituto de Enseñanza Media, gestión turística y patrimonial y gestión del agua. Ambas comarcas tienen una importante especialización turística. Pero mientras que en Alta Cerdanya son muy importantes los servicios asistenciales (Moncusí, 2004), en Baixa Cerdanya el crecimiento económico principal se ha basado en la promoción de segundas residencias (DPTOP, 2009), modelo que como hemos visto, ha tocado techo en atención a la reducción del sector de la construcción (ver Figuras 10 y 11). Tampoco está asegurado el modelo asistencial de Alta Cerdanya, actualmente en retroceso por la reducción en servicios públicos. La proximidad de ambas comarcas con Barcelona y su área metropolitana es una oportunidad insuficientemente aprovechada. Pero para atraer e impulsar nuevas inversiones, es necesario un proceso estratégico. Establecer planes de desarrollo común reforzando el modelo de cooperación institucional entre Alta y Baixa Cerdanya, extenderlo hasta Alt Urgell y vincularlo con la cooperación ya iniciada en desarrollo rural se presenta como una oportunidad para encauzar dicha estrategia. A pesar de la vecindad con Andorra y con la comarca de Baixa Cerdanya, importantes destinos turísticos en ambos casos, el turismo en Alt Urgell tiene aún poco impacto y las segundas residencias son un fenómeno tardío, sin posibilidades de prosperar actualmente.

\footnotetext{
34. Denominación de Origen Protegida (DOP) para la mantequilla y el queso de la Cooperativa Cadí e Indicación Geográfica Protegida (IGP) para la Vedella Bruna del Pirineu.
} 
La segunda residencia en Alt Urgell (2.143 unidades de viviendas secundarias, 3.867 si les sumamos las viviendas vacantes) representada el 19,69\% (35,53\% secundarias con vacantes) sobre el total de viviendas (7.017) del área en 2001.

La crisis económica, además de limitar las ofertas de empleo de Andorra, ha reducido la afluencia de visitantes, que en 2004 habían alcanzado los 11.668.460, mientras que en 2009 se habían reducido a 2.837.64635, también por motivos de exclusión de la movilidad laboral en el cómputo. Esta situación marca un nuevo escenario para Alt Urgell, por lo que el modelo actual de dependencia e interacción con Andorra pediría un cambio de estrategia que pasaría por entender Andorra también como un centro receptor de servicios y no solo emisor. Sin duda la disponibilidad de patrimonio natural y cultural es el principal activo de toda la región. Una apuesta clara por acciones de desarrollo rural y sostenible se muestra como la línea más coherente con el territorio tomando como eje estratégico el sector agroalimentario y el turismo verde. Ésta permitiría además introducir medidas de requilibrio territorial entre las cuatro áreas de la región, en las que actualmente se detectan importantes disparidades de concentración espacial (ver Figuras 6 y 7).

A priori, los tres enfoques para abordar las fronteras que distingue Houtum (2002) son válidos para interpretar la región transfronteriza que tratamos, dado que en ella se generan flujos, existe cooperación y hay pervivencia de un trasfondo cultural común. Sin embargo, se trata de cooperaciones parciales de distinta naturaleza entre las cuatro áreas. Probablemente, no favorecerá la integración de la región el hecho de que se trate de un territorio con escasa y envejecida población, en su mayor parte. Otro condicionante posible sea que la mayor concentración de población se localice precisamente en el micro-estado de Andorra, que aunque con acuerdos parciales con la UE, no es estado miembro. La geografía de montaña es otro factor decisivo más, elevando los costes en infraestructuras de comunicación y dificultando el establecimiento de redes de cooperaciones internas y externas, al estar a más de dos horas de las ciudades del sur de Francia y del norte de España. Sin duda, estas son algunas de las razones que explican también la baja participación de este territorio en los proyectos de cooperación de la Comunidad de Trabajo de los Pirineos ${ }^{36}$ (CTP) entre Andorra, España y Francia cuyo ámbito incluye las cuatro áreas de estudio. Las distintas ediciones del programa Interreg (Abuin, 2007) reflejan la versatilidad y posibilidades en cooperación. Se contabilizan nueve proyectos de cooperación cofinanciados por el programa Interreg 2000-2006 y 2007-201337, la mayoría encabezados por entidades locales públicas y privadas de Alta y Baixa Cerdanya para acompañar el proceso de estudio y ejecución del Hospital y el

35. Datos obtenidos en: http://www.estadistica.ad [Consultado: 26-03-13].

36. La región transfronteriza CTP corresponde al tipo de macro-cooperación emergente de nivel regional (Oliveras et al., 2010).

37. http://www.poctefa.eu/ [Consultado: 11-04-13]. 
Matadero transfronterizos. El resto son proyectos liderados por entidades de nivel subnacional, superior a estas comarcas, aunque sobre los mismos conceptos. A nivel puntual, se registran proyectos de gestión del agua, liderados por entidades públicas y privadas en las mismas comarcas mencionadas, uno de ellos con Alt Urgell como socio. Otros proyectos puntuales son los de centros tecnológicos y universidades de todo el ámbito de la CTP participados por Andorra en calidad de socio, sobre temas de investigación ambiental y docencia universitaria. A pesar de ser limitados en su número, los proyectos de cooperación transfronteriza liderados o participados por organismos de las zonas de estudio, han proporcionado efectos demostrativos a la población. Es especialmente valioso el modelo de gestión transfronteriza de la AECTPC, suponiendo el reconocimiento definitivo de que las regiones y los entes locales pueden y deben colaborar con otras entidades europeas para lograr cohesión territorial (Beltran, 2010).

Menos impacto ha tenido en la zona la creación en 2004 de la Eurorregión PirineosMediterránea (Aragón, Cataluña, Islas Baleares, Midi-Pyrénées y Languedoc-Roussillon), que a pesar de sus potencialidades tiene aún un incipiente grado de implementación (Morata, 2010). A pesar de ello, la mega región del Eje Mediterráneo representa una nueva escala que habrá que considerar en el momento de planificar (Boira, 2010).

Se puede identificar en la región estudiada, de acuerdo con la tipología de Oliveras et al. (2010), una cooperación transfronteriza de tipo micro-cooperación integrada local en el caso de Alta Cerdanya con Baixa Cerdanya. En el caso de Andorra con Alt Urgell, se reconoce el tipo de macro-cooperación emergente de baja intensidad asociada al nivel regional si es mediada por la Generalitat de Catalunya (NUTS 2), cuando dispone de las competencias ejecutivas ${ }^{38}$. A nivel informal, no obstante, la interacción Andorra-Alt Urgell es muy intensa y complementaria (Pallarès-Blanch et al. 2005). Ambos tipos de cooperación; Alta Cerdanya-Baixa Cerdanya y Andorra-Alt Urgell se ajustan también al modelo que señala Medeiros, de cooperación estructural entre regiones por razones históricas y culturales y por existir acuerdos funcionales y operativos entre instituciones de ambas áreas (Medeiros 2011 en Nelles y Walther, 2011). En ambos casos, a pesar de los flujos y los vínculos históricos y culturales, las relaciones de complementariedad son asimétricas. Aunque toda la comunidad comparta una identidad cultural y lingüística común, y de existir una elevada permeabilidad entre la frontera francoespañola (Moncusí, 2005; 2008; Tulla, 1977; 1997), las cooperaciones transfronterizas institucionales son aún poco funcionales (Maury et al. 2011), aunque sean más simétricas y de naturaleza más horizontal en el caso de Alta Cerdanya-Baixa Cerdanya. En cambio, las relaciones Alt Urgell-Baixa Cerdanya, y las que se dan entre Alta Cerdanya y Andorra, son más "de hecho" que institucionales (ver Figura 12).

38. Oliveras et al. (2010) definen cooperación territorial cuanto se da a nivel sub-nacional, es decir, sub-estatal. 
Las variaciones expuestas en los grados de cooperación institucional y en los tipos de interacciones transfronterizas reflejan su propia complejidad, produciéndose solapamientos territoriales e identidades ambivalentes (Retaillé, 2011; Kessler, 2007; Anderson, 1999).

Es previsible que frente a las necesidades de re-dinamización económica, a pesar de las centrípetas formas de gobierno de los Estados-nación (Scott, 2012; Maury, 2011; Ensellem, 2010), los beneficios de la cooperación surjan como nuevas oportunidades para esta región, como así se ha producido en otras regiones transfronterizas europeas (Isfanescu, 2011). Asimismo, la creciente necesidad de abordar la planificación territorial con estructuras administrativas más horizontales puede suponer un reto para remediar la ausencia de gobernanza en la cooperación transfronteriza (Ensellem, 2010, Maury, 2011), y un incentivo para un desarrollo local y territorial aunado (Ensellem, 2010; Happaerts et al. 2010).

\section{Conclusiones}

La Región de la Cuenca del Alto Segre constituye una unidad geográfica formada por valles pirenaicos comunicados por una misma red hidrográfica. Estos mantuvieron una organización política común entre los siglos VIII y XIII. En el siglo XXI permanece dividida en cuatro áreas repartidas entre España, Francia y Andorra, por razones político-administrativas. A nivel histórico y cultural las cuatro áreas comparten tradiciones socioeconómicas en aspectos como los tipos de explotación agraria, estrategias de supervivencia en el pasado, como la emigración estacional o definitiva a Barcelona o al sur de Francia y el contrabando como recurso económico fuera de la ley. Esta organización socio-cultural estuvo plenamente vigente hasta mediados del siglo XX, mientras la actividad agropecuaria preponderó, manteniéndose relaciones transfronterizas fluidas en cuanto a la producción y distribución. En el aspecto cultural, la región conserva una identidad lingüística común con diglosias diferentes de la lengua catalana, además de lazos familiares transfronterizos (vínculos, relaciones estratégicas, elementos patrimoniales y de herencia) y celebraciones conjuntas entre Alta Cerdanya y Baixa Cerdanya. A nivel de centros de mercado, la capitalidad de Puigcerdà para Alta Cerdanya y Baixa Cerdanya ha perdurado a través de los siglos, mientras que para Andorra y Alt Urgell, La Seu d'Urgell se mantuvo como principal centro comercial hasta mediados del siglo XX, cuando Andorra inicia la expansión de los servicios turísticos, comerciales y financieros. Aun así, el mercado y los comercios de La Seu d'Urgell siguen siendo frecuentados por los residentes andorranos.

A nivel demográfico se identifican dos tendencias: la del crecimiento exponencial de Andorra y la del estancamiento por envejecimiento del Alt Urgell, Alta Cerdanya y Baixa Cerdanya, con una leve recuperación demográfica por la reciente inmigración, actual- 
mente en receso debido a la crisis del modelo de desarrollo turismo-construcción. A nivel económico, se trata de un territorio que ha cambiado en pocas décadas su secular base agraria y ganadera por el dominio del sector terciario, especializado en el turismo. Esta evolución se ha producido a diferentes ritmos según las áreas, conformándose dos modelos de desarrollo; el modelo de crecimiento acelerado de Andorra del que participan, en parte, Alta y Baixa Cerdanya y el modelo de desarrollo rural lento de Alt Urgell, que influye sectorialmente a Baixa Cerdanya, sobretodo, y también a Alta Cerdanya, a través del consolidado clúster agro-alimentario. Alt Urgell participa indirectamente del modelo de Andorra por la dependencia con ésta como proveedor de puestos de trabajo, ahora en declive. Baixa Cerdanya ha basado su terciarización con la construcción de segundas residencias, sector en crisis actualmente. Por otro lado, Alta Cerdanya y Baixa Cerdanya son las dos áreas que muestran mayor capacidad de cooperación, en vista a los proyectos de servicios compartidos y la creación de la AECTPC para gestionarlos.

El proceso de terciarización ha acentuado las diferencias entre los dos modelos de especialización económica, aunque con estrategias de cooperación, las dos especializaciones, la turística y de servicios, y la rural, podrían ser más complementarias de lo que actualmente son. El punto clave es poder mantener un sector agrario que esté integrado en la promoción turística a través del agroturismo, o de los productos agrarios de calidad.

En este estudio sobre las interacciones y la cooperación institucional entre las cuatro áreas se ponen de relieve las ventajas y oportunidades que supondría un proyecto de cooperación común en la región. Sin embargo, el mismo análisis muestra también la existencia de barreras institucionales para la cooperación transfronteriza desde los estamentos superiores debido a las diferentes regulaciones entre estados. Asimismo, a nivel popular y según las circunstancias, la experiencia de frontera puede ser retratada como una frontera fácilmente superable, una realidad administrativa limitante, o bien un símbolo de unidad. La mayor conciencia sobre las oportunidades que representaría una cooperación transfronteriza articulada entre las cuatro áreas se encuentra entre algunos responsables políticos locales, entre especialistas en desarrollo local y entre las personas y entidades más comprometidas con el territorio.

El actual contexto de crisis acrecienta la necesidad de economizar infraestructuras y servicios e implementar proyectos de desarrollo, entre las áreas tratadas, complementarios y requilibradores. Los programas de cooperación transfronteriza de la UE pueden proporcionar el marco adecuado para conocer las externalidades comunes, compartir y consolidar servicios y equipamientos y, en un futuro, asentar las bases para asentar un modelo de desarrollo local común. Al tratarse de unidades territoriales con estructuras administrativas distintas hay una jerarquía y capacidad de gestión diferente para cada una de ellas, con situaciones tan dispares como Andorra, un estado soberano y fuera de la UE, Alt Urgell y Baixa Cerdanya, dos comarcas que pertenecen a España y que con ello cuentan con el apoyo de la Comunidad Autónoma de Cataluña y Alta Cerdanya en Francia, con un modelo territorial más centralista. En este sentido, las 
AECT son los instrumentos que permiten promover acciones de cooperación transfronteriza de impulso local mediante una gobernanza multinivel que facilita el intercambio horizontal entre entidades locales. Aparece así, el desarrollo de consorcios regionales con estados vecinos como una nueva red de cooperación, en la que el rol de la sociedad civil es clave, fomentando nuevas formas de cooperación en la emergente Europa de la vecindad. Son ejemplos de ello las delegaciones locales de sindicatos sectoriales y de agrupaciones comerciales, así como asociaciones socio-culturales. Así y al margen de la importancia de las jurisdicciones administrativas, existen otras identidades solapadas, por razones socio-económicas, culturales y familiares, que conectan con el origen común de los cuatro territorios. Integrar estos elementos de identidad en la gobernanza para la cooperación territorial transfronteriza, mediante la participación de sus actores como representantes de las redes informales de cooperación, puede ser el incentivo para trabajar conjuntamente en la perspectiva de un desarrollo sostenible.

\section{Agradecimientos}

Las autoras y el autor aprecian el tiempo que nos han dedicado Joseph Domínguez, Maite Espinach, Carles Gascón, Erola Simon y las personas portavoces de las entidades consultadas y citadas en el apartado sobre metodología. Agradecen el tiempo que ha proporcionado la Fundación CEDRICAT a Marta Pallarès-Blanch, mediante el programa Talent-Empresa. Asimismo, valoran las indicaciones ofrecidas por los evaluadores del artículo.

\section{Bibliografía}

Abuin, E. (2007) "La cooperació transfronterera, transnacional i interregional a Catalunya" Nota d'Economia, 88, pp. 153-166.

Anuari Econòmic Comarcal (2007) Caixa de Catalunya.

Arqué, M., Garcia, A., Mateu, X. (1982) La penetració del capitalisme a les comarques de 1'Alt Pirineu. Documents d'Anàlisi Geogräfica, Universitat Autònoma de Barcelona, 1: 9-67.

Anderson, J. y O'Wood, L. (1999) Borders, Border Regions and Territoriality: Contradictory Meanings, Changing Significance. Regional Studies, 33 (7): 593-604.
Barrachina, M. y Tulla, A.F. (2010) Els canvis socioambientals al Pirineu català: la Vall Fosca com a escenari representatiu de les mutacions en les economies tradicionals de muntanya. Documents d'Anàlisi Geogràfica, 56 (3): 557-572.

Beltran, S. (2010) Els organismes de cooperación territorial a Europa: una mirada cap al futur. Documents d'Ànàlisi Geogràfica, 56 (1): 57-69.

Bernardos Domínguez, G. (2009) Creación y destrucción de la burbuja inmobiliaria en España, Información Comercial Española, 850: 23-40. 
Boira, J.V. (2010) L’Eix Mediterrani: entre les dinàmiques locals i la perspectiva megaregional. Documents d'Anàlisi Geogräfica, 56 (1): 91-109.

Bricall, J.M. et al. (2001) L'economia andorrana en el canvi de segle. Andorra, Fundació Julià Reig.

Bricall, J.M., Camps, C., Cullell, J.M., Farré-Escofet, E.P., Petitbò, A., Sogues, J. y Tomàs, R. (1975) Estructura i perspectives de l'economia Andorrana. Barcelona, Edicions 62.

Burgueño, J. (1995) De la Vegueria a la Provincia. La formació de la divisió territorial contemporània als Països Catalans (17901850). Barcelona, Rafael Dalmau Editors.

Clout, H.D. (1986) Regional variations in the European Community. Cambridge University Press, Cambridge.

Dirección General de Coordinación de Competencias con las Comunidades Autónomas y las Entidades Locales (2013) Las Agrupaciones Europeas de Cooperación Territorial (AECT). Última actualización: junio de 2013. Secretaría de Estado de Administraciones Públicas. Secretaría General de Coordinación Autonómica y Local. Ministerio de Hacienda y Administraciones Públicas del Gobierno de España.

Emsellem K., Basse R.M., Voiron-Canicio C. (2010) Mitos y realidades de la cooperación en el espacio transfronterizo francés, italiano y monegasco. Documents d'Anàlisi Geogràfica, 56 (1): 111-131.

Flockton, Ch., Kofman, E. (1989) France. London, Paul Chapman Pub. Ltd.

Comas d'Argemir, D. (1995) La definición de la cultura pirenaica, en Bertranpetit, J. i Vives, E. (eds.): Muntanyes i població. El passat dels Pirineus des d'una perspectiva multidisciplinària, Andorra, Ministeri de Relacions Exteriors del Govern d'Andorra/Centre de Trobada de les Cultures Pirinenques: 333-344.
Gascón, C. (2009) "Cadí, la 'comprativa' de la llet”, Cadi-Pedraforca, 7, pp. 42-46.

Gascón, C. (2010) Comarques oblidades: Josep Zulueta $i$ el Pirineu l'any 1890, La Seu d'Urgell, Edicions Salòria.

Departament de Política Territorial i Obres Públiques -DPTOP- (2009) Plans Comarcals de Muntanya 2009-2012. Retrats. Generalitat de Catalunya.

Happaerts, S., Van Den Brande, K. y Bruyninckx, H. (2010) Governance for Sustainable Development at the Inter-subnational Level: The Case of the Network of Regional Governments for Sustainable Development (nrg4SD) Regional and Federal Studies, 20 (1): 127-149.

Hartshorne, R. (1932) The twin city district: a unique form of urban landscape. Geographical Review, 22: 431-442. American Geographical Society.

Houtum, H. van (2002) Introduction: Current Issues and Debates on Borders and Border Regions in European Regional Science. In: M. van der Velde and $\mathrm{H}$. van Houtum (eds.), Borders, Regions and People. London, Pion Limited; 1-13.

IDESCAT (2011) Cens Agrari 2009, Barcelona, Generalitat de Catalunya.

Isfanescu, R. (2011) La frontière: barrière ou élément d'amplification des initiatives entrepreneuriales? Étude de cas: la zone de frontière du Banat: 133-145 en Ioan Ianos, Nicolae Popa, Andreea Loreta Cercleux (eds) Roumain. Éléments de planification territorial et développement régional. Bucarest, Editura Universitara.

Kessler, O. y Helmig, J. (2007) Of Systems, Boundaries, and Regionalisation. Geopolitics, 12 (4): 570-585.

Llobet, S. (1947) El medio y la vida en Andorra. Barcelona, C.S.I.C. - Instituto Juan Sebastián Elcano - Estación De Estudios Pirenaicos. 
Lluelles, M.J. (2007) La transformació econòmica d'Andorra durant el segle XX, Treballs de la Societat Catalana de Geografia, 64: 71-88.

Maury, C. y Richard, S. (2011) La difficile gestion de l'eau en contexte transfrontalier: un exemple franco-espagnol. J. Nelles y O. Walther (eds.), Journal of Urban Research, 6 pp. (revista electrónica).

Margarit, E. (2012) Les relacions frontereres entre el Principat d'Andorra i l'Alt Urgell. Centre de Recerca Sociològica de l'Institut d'Estudis Andorrans. Andorra, Pagès Editors.

Mármol, C. del y Gascón, C. (2011) Muntanyes de Formatge. Transformacions productives i patrimonialització a l'Urgellet i el Baridà. Memoria del Proyecto de Investigación "En terra de llet i formatge" del Programa de recerca anàlisi 2009 de l'Inventario del Patrimonio Etnológico de Catalunya (IPEC), 2009-2011. Documento digital.

Medeiros E. (2011) (Re)defining the Euroregion concept. European Planning Studies 19, (1): 141-158.

Moncusí, A. (2004) Vora una ratlla que "hi és però com si no hi fós": Frontera i límits nacionals a la Cerdanya. Quaderns de Ciències Socials. Facultat de Ciències Socials. Universitat de València, 11: 5-57.

Moncusí, A. (2005) Fronteres, identitats nacionals i integració europea. El cas de la Cerdanya. Catarroja (País Valencià), Editorial Afers.

Moncusí, A. (2008) "Fronteres i evolucions locals: el cas de la Cerdanya". Mirmanda, 3 : 58-66.

Morata, F. (2010) Euroregions i integració europea. Documents d'Anàlisi Geogràfica, 56 (1): 41-56.

Nelles J. y Walther O. (2011) Changing European borders: from separation to interface? An introduction. Articulo, Journal of Urban Research, 6 pp. (revista electrónica).
Newman, D. (2006) The lines that continue to separate us: borders in our 'borderless' world. Progress in Human Geography, 30 (2): 143161.

Niebuhr A. y Stiller S. (2002) Integration effects in border regions. A survey of economic theory and empirical studies. European Regional Science Association Conference Papers 66, citado por Oliveras, X.; Durà, A.; Perkmann, M. (2010): Las regiones transfronterizas. Documents d'Anàlisi Geogràfica, 56 (1): 21-40.

Paasi, A. (2003) Region and place: regional identity in question. Progress in Human Geography, 27 (4): 475-485.

Pallares-Blanch, M., Tulla, A.F., Pallares-Barberà, M. (2005) L'impacte socioeconòmic del principal d'Andorra a les comarques veïnes. El cas de la Seu d'Urgell i àrea d'influència. En: V. Pou Serradell (coord.): $L a$ balança de fets i pagaments del principal d'Andorra: 83-160. Andorra, Centre de Recerca d'Afers Exteriors.

Pallarès-Blanch, M. y Tulla, A.F. (2011) El model de ciutats bessones en una àrea de muntanya. Les relacions de frontera Andorra-Espanya (la Seu d'Urgell i àrea d'influència): 101-114, en Òscar Jané y Queralt Solé (eds.): Observar les fronteres, veure el món. Catarroja-Figueres-Perpinyà Mirmanda y Editorial Afers.

Pallarès-Blanch, M., Prados, M.J., Tulla, A.F. (2014, en prensa) "Naturbanization and urban-rural dynamics in Spain: case study of new rural landscapes in Andalusia and Catalonia", European Countryside (electronic paper), Vol. 6, number 2.

Pallares-Barbera, M., Tulla, A.F., Vera, A. (2004) Spatial loyalty and territorial embeddedness in the multi-sector clustering of the Berguedà region in Catalonia (Spain). Geoforum, 35 (5): 635-649. 
Perkmann, M. (2003) Cross-Border Regions in Europe: Significance and Drivers of Regional Cross-Border Co-Operation. European Urban and Regional Studies, 10: 153-171.

Pou I Serradell, V. (1994) Andorra, el GATT I la Nova Organització Mundial del Comerç: Anàlisi i documentació sobre la situació d'Andorra en el nou ordre comercial internacional. Crèdit Andorrà, Andorra.

Pou I Serradell, V. (2002) Andorra-Unió Europea. Opcions de futur. Andorra, Crèdit Andorrà.

Retaillé D. (2011) La transformation des formes de la limite. Journal of Urban Research 6, http://articulo.revues.org/1723.

Romero González, J. (2009) Geopolítica y gobierno territorial en España. Colección Crónica. Valencia, Tirant lo Blanch.

Sahlins, P. (1989) Boundaries. The Making of France and Spain in the Pyrenees. Oxford, University of California Press Ltd.

Scott, J.W. (2012) European Politics of Borders, Border Symbolism and Cross-Border Cooperation: 83-100. T.M. Wilson y H. Donnan (eds.): A Companion to Border Studies. Chichester, Blackwell Companions to Anthropology.

Scott, J.W y Liikanen, I. (2010) Civil Society and the 'Neighbourhood' - Europeanization through CrossBorder Cooperation? Journal of European Integration, 32 (5): 423-438.

Smith, D.M. (1975) Patterns in Human Geography. Harmondsworth, Penguin.

Suné, J.F. (2012) La instal-lació de joves agricultors a Catalunya del Nord. Comunicación del Secretario general del Sindicato de Jóvenes Agricultores de los Pirineos Orientales. XXVII Jornada d'Agricultura a Prada. Universitat Catalana d'Estiu. Els joves i la dinamització del sector agrari. Institució Catalana d'Estudis Agraris (ICEA), Secció de Ciències Biològiques de l'Institut d'Estudis
Catalans. Sábado, 18 de agosto de 2012, Liceu Renouvier de Prada de Conflent.

Tulla, A.F. (1977) Les deux Cerdagnes. Exemple de Transformations économiques asymétriques de part et d'autre de la frontière des Pyrenées. Revue Géographique des Pírense et du Sud-ouest, Tome 48, fasc. 4: 404-424.

Tulla, A.F. (1984) L'avantatge comparatiu en àrees rurals de muntanya en Recerques, 16: $51-70$.

Tulla, A.F. (1993) Procés de transformació agrària en àrees de muntanya. Barcelona, Institut Cartogràfic de Catalunya, Generalitat de Catalunya.

Tulla, A.F. (1997) La Cerdanya: dues realitats un espai comú: 83-104, en Jordi Domingo y Lluís Mallart (eds.) A l'entorn de la frontera. Barcelona, Oikos-Tau.

Tulla, A.F., Pallares-Blanch, M., Vera, A. (2007) The new urban centrality in a mountainous rural area in the frontier: Andorra and Seu d'Urgell twin cities: 62-64, en Kallabová, E; Frantál, B I Klusá ek, P. [Eds.] Regions, Localities and Landscapes in New Europe. Brono (República Checa), Academy of Sciences of the Czech Republic, Institute of Geonics.

Tulla, A.F., Vera, A., Pallares-Blanch, M., Pallares-Barbera, M. (2008) La frontera y el modelo de regiones gemelas: 511-524. Feria Toribio, J.M., García García, A., Ojeda Rivera, J.F. (eds.), Territorios, Sociedades, Políticas. Sevilla, AGE y Universidad Pablo de Olavide.

Tulla A.F., Pallarès-Blanch M. (2008) La mobilitat quotidiana a l'Alt Pirineu i Aran. Revista Papers, 48 (La Mobilitat Quotidiana a Catalunya, 2006), pp. 100-113. Barcelona. Institut d'Estudis Regionals i Metropolitans de Barcelona. http://www.iermb.uab.es/htm/revistaPapers_numeros.asp?id=53. [Consulta: $14-$ 05-13]. 
Tulla, A.F., Pallares-Barbera, M., Vera, A. (2009) Naturbanization and Local Development in the mountain areas of the Catalan Pyrennes: 75-92. Prados, M.J. [Ed.]. Naturbanization. New identities and processes for rural - natural areas. Londres, Taylor \& Francis.
Valls, F., Soldevila, F. (2002) Història de Catalunya. Barcelona, L'Abadia de Montserrat.

Vila, P. (1926) La Cerdanya. Barcelona, Ed. Barcino. 